\title{
Compliance with a Nurse-driven Hypoglycemia Protocol: Time from Hypoglycemia Event to Euglycemia
}

Robin A. Chappell

University of St. Augustine for Health Sciences, rchappell3@me.com

DOI: https://doi.org/10.46409/sr.IJN06581

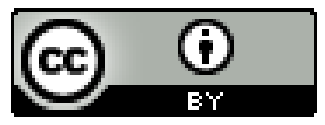

This work is licensed under a Creative Commons Attribution 4.0 License.

Follow this and additional works at: https://soar.usa.edu/scholprojects

Part of the Endocrine System Diseases Commons, Nursing Administration Commons, and the Other Nursing Commons

\section{Recommended Citation}

Chappell, R. A. (2021). Compliance with a Nurse-driven Hypoglycemia Protocol: Time from Hypoglycemia Event to Euglycemia. [Doctoral project, University of St Augustine for Health Sciences]. SOAR @ USA:

Student Scholarly Projects Collection. https://doi.org/10.46409/sr.IJN06581

This Scholarly Project is brought to you for free and open access by the Student Research at SOAR @ USA. It has been accepted for inclusion in Student Scholarly Projects by an authorized administrator of SOAR @ USA. For more information, please contact soar@usa.edu, erobinson@usa.edu. 
Compliance with a Nurse-driven Hypoglycemia Protocol: Time from Hypoglycemia Event to Euglycemia

Robin Chappell, MSN, ACNS-BC, APN

School of Nursing, University of St. Augustine for Health Sciences

This Manuscript Partially Fulfills the Requirements for the Doctor of Nursing Practice Program and is Approved by:

Jennifer Mensik Kennedy, PhD, MBA, RN, NEA-BC, FAAN

Darcy Copeland, $\mathrm{PhD}, \mathrm{RN}$

Approved: Written as March 25, 2021 
Certified by Adobe Sign, a Document Cloud solution <adobe-sign-

( certified@adobe.com>, prod-hsm, certificate issued by Adobe CDS CA. You cannot save data typed into this form.

Please print your completed form if you would like a copy for your records.

University of St. Augustine for Health Sciences DNP Scholarly Project

Signature Form

\begin{tabular}{l|l}
\hline Student Last Name: & $\begin{array}{l}\text { First } \\
\text { Chappell }\end{array}$ \\
\hline E-mail: \\
R.Chappell@ usa.edu
\end{tabular}

Title of DNP Project:

Compliance with a Nurse-driven Hypoglycemia Protocol: Time from Hypoglycemia Event to Euglycemia

My signature confirms I have reviewed and approved this final written DNP Scholarly Project. DocuSign electronic signature or wet signature required.

\begin{tabular}{|l|c|l|}
\hline Type Name in Blue Box Below & Signature & Date \\
\hline $\begin{array}{l}\text { DNP Project Primary Faculty: } \\
\text { Jennifer Mensik Kennedy }\end{array}$ & Jennifer Mensik Kennedy & $3 / 24 / 2021$ \\
\hline $\begin{array}{l}\text { DNP Project Preceptor: } \\
\text { Darcy Copeland }\end{array}$ & DarCy Copeland & $3 / 25 / 2021$ \\
\hline DNP Project Preceptor: & \\
\hline
\end{tabular}

signature: Jennifer Mensik Kennedy

Email: jmensik@usa.edu

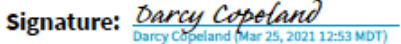

Email: darcy.copeland@unco.edu 


\begin{abstract}
Practice Problem: Hypoglycemia is a known complication of diabetes mellitus and is considered one of the top three adverse drug events by the U.S. Department of Health and Human Services (2019) because it is common, clinically significant, measurable, and preventable.
\end{abstract}

PICOT: The PICOT question that guided this project was: In non-critical hospitalized adult patients on medical-surgical units with documented HGEs, how does active surveillance for strict adherence to a nurse-driven hypoglycemia protocol, compared to no surveillance, affect the time from hypoglycemia to euglycemia?

Evidence: Treatment of hypoglycemia is commonly inconsistent and prolonged; however, active surveillance and monitoring of a nurse-driven protocol by diabetes nurses has improved hypoglycemia protocol adherence and the time from a hypoglycemia event to euglycemia. Intervention: Education regarding the physiological effects of hypoglycemia and treatment was provided to medical-surgical nurses. Active surveillance/medical-surgical unit rounding was instituted by a registered nurse diabetes clinical coordinator focusing on adherence to the established nurse-driven hypoglycemia protocol.

Outcome: The DCC rounding proved clinically significant as adherence to each component of the protocol improved. The time from HGE to euglycemia improved, and a statistically significant improvement in nursing knowledge related to the physiological effects of hypoglycemia and treatment was identified.

Conclusion: Continued emphasis on nurses' adherence to the hypoglycemia protocol through DCC surveillance and additional innovative practices is necessary for improved patient outcomes. 


\section{Compliance with a Nurse-driven Hypoglycemia Protocol: Time from Hypoglycemia Event to Euglycemia}

Diabetes mellitus (DM) is a chronic, metabolic disease characterized by increased levels of blood glucose. Poorly managed DM is a major cause of heart attacks, strokes, and other complications (Forouhi \& Wareham, 2014; World Health Organization [WHO], 2018). In 2016 DM was estimated to be the seventh leading cause of death around the world (WHO, 2018) and the number one cause of lower-limb amputations, kidney failure, and adult blindness in the United States (Centers for Disease Control and Prevention [CDC], 2020). Exactly how many people die from DM is difficult to ascertain since DM adversely affects multiple physiological systems and death is often attributed to the end-organ failure resulting from poor glycemic control (Kim et al., 2019).

Hypoglycemia is a known complication of DM treatment and is defined as a blood glucose value of $\leq 70 \mathrm{mg} / \mathrm{dL}$ (American Diabetes Association [ADA], 2020, p. S196). Hypoglycemia is considered one of the top three adverse drug events (ADE) requiring an action plan because it is common, clinically significant, measurable, and preventable (U.S. Department of Health and Human Services, 2019). Significant neurological, neurocognitive, cardiovascular, and visual physiological adverse effects and risks are precipitated by hypoglycemia (Kalra et al., 2013). This paper outlines the implementation of an evidence-based practice (EBP) project introducing active surveillance for strict adherence to a nurse-driven hypoglycemia protocol. The clinical outcome measure is to evaluate whether the nurses' strict adherence to the protocol decreases the time from an initial hypoglycemia event (HGE) to euglycemia. 
The WHO (2018, para.1) reported that the number of people across the globe living with DM rose from 108 million in 1980 to 422 million in 2014. The CDC (2020, p.4) stated that in the United States, 34.2 million people had diabetes; 7.3 millions of those people were undiagnosed. In 2017, 7.4\% of Coloradoans and 5.7\% of Jefferson County citizens self-reported having DM (Jefferson County Public Health Department, 2018, Diabetes graph). Although Colorado and Jefferson County have a low prevalence of DM, approximately $35 \%$ of all patients admitted to the hospital in which this project took place, have a diagnosis of DM.

In 2015, an estimated 1.31 trillion dollars were spent globally on diabetes (Bommer et al., 2017, p. 423). In 2017, the total direct and indirect cost of diagnosed DM in the United States was assessed to be 327 billion dollars (ADA, 2018, p. 924). People with DM spend 2.3 times more on healthcare costs than those without DM (ADA, 2018, p. 926). On average, an individual diagnosed with DM spends $\$ 16,752$ per year on medical expenses including hospital inpatient care, prescription medications with supplies, and physician visits (ADA, 2018, p. 917). Diabetes mellitus impacts the individual, family, and community through decreased quality of life, lost productivity through work absenteeism, loss of work entirely from disability, and lost productivity due to early mortality (ADA, 2018).

Patients with DM require frequent hospitalizations due to the disease process and related multiorgan complications (Mandel et al., 2019; Robbins et al., 2019; Winterstein et al., 2018). Glycemic variability while hospitalized is a significant risk factor for complications, poor outcomes, increased length of stay (LOS), mortality, and readmission (Aloi, et al., 2015; Robbins et al., 2019). Hypoglycemia is a leading limiting factor in glycemic control efforts (Society of Hospital Medicine [SHM], 2015). The incidence of HGE is common (Cruz, 2020), but estimates have varied from $2.8 \%$ to $33.5 \%$ (SHM, 2015, p. 135). Hypoglycemia can lead to seizures, 
stroke, autonomic failure, arrhythmias, cognitive decline, and death (Araque et al., 2018; SHM, 2015).

\section{PICOT Question}

In non-critical hospitalized adult patients on medical-surgical units with documented HGEs, how does active surveillance for strict adherence to a nurse-driven hypoglycemia protocol, compared to no surveillance, affect the time from hypoglycemia to euglycemia?

\section{Population}

The population included in this project were patients 18 years old and older with a documented HGE during their medical-surgical hospital stay. Population exclusion criteria was based on the glucometrics outlined by the SHM (2015). Patients considered actively dying, using the concept of hours or days of survival (Hui et al., 2014), were excluded from the population. Additional population exclusions were patients with a primary diagnosis of diabetic ketoacidosis (DKA) or hyperglycemic hyperosmolar state (HHS), patients with provider orders not to treat the HGE such as palliative care or diagnostic tests, and those with less than four documented blood glucose values (SHM, 2015).

\section{Intervention}

The intervention involved the introduction of a registered nurse $(\mathrm{RN})$ diabetes clinical coordinator (DCC) performing active surveillance on HGEs that occurred on noncritical medical-surgical inpatient units. The DNP student coordinated the active surveillance unit rounds as well as real-time or written feedback to nursing associates for hypoglycemic events. When rounding on the units, the student and DCC provided focused attention to the treatment of hypoglycemia and adherence to an evidence-based hypoglycemia treatment protocol. The student also collaborated with a diabetes interdisciplinary team (IDT) to deliver hypoglycemia 
education to the nursing and medical staff. This EBP project incorporated definitions of hypoglycemia and other glucometrics as outlined in the standards of hospital medical care in diabetes (ADA, 2020). Hypoglycemia is defined as a blood glucose level $\leq 70 \mathrm{mg} / \mathrm{dL}$ (ADA, 2020, p. S196) and hyperglycemia as $\geq 180 \mathrm{mg} / \mathrm{dL}$ (ADA, 2020, p. S194).

\section{Interdisciplinary Team Specifics}

The diabetes IDT continued normal activities and is comprised of an endocrinologist, registered nurse DCC, registered dietician, certified diabetes educator, and clinical nurse specialist. The DNP student was an addition to the existing team. One person fulfilled the duties of more than one role. For example, initially, the registered dietician also performed the role of the certified diabetes educator. The endocrinologist served as the glycemic management clinical expert, offering provider coaching for hypoglycemia protocols, and assisted with the hypoglycemia protocol review. The DNP student, along with the DCC and the clinical nurse specialist, provided diabetes expertise, leadership, and education for the nurses and nursing assistants working on the medical-surgical units. The registered dietician/certified diabetes educator continued teaching dietary recommendations and offered patient education. Lastly, the DNP student maintained the structure of the project, controlled and monitored progress, analyzed data for accuracy, and presented project results.

In addition to the IDT, other stakeholders were vital to the success of the project. The stakeholders for this project included representatives of bedside nurses and nursing assistants as well as the hospitalist, trauma, and general surgery provider groups. Key stakeholders included the organization's Internal Review Board (IRB), the University of Saint Augustine for Health Sciences Review Board, the organization's patient representative and quality director, the endocrinologist medical director, and the executive leaders. 


\section{Comparison Group and Outcomes}

The comparison in this question was patients receiving usual care, which did not include a dedicated DCC performing active surveillance. The primary outcome measured was the length of time, in minutes, from the initial hypoglycemic event (HGE) to euglycemia. The project time was 10 weeks. The time from HGE to euglycemia was expected to decrease during the 10 weeks. Contextual, process, financial, sustainability and balancing measures were also evaluated at the conclusion of the project. These additional measures will be discussed later in this paper.

\section{Quality Improvement Framework and Change Theory}

This proposed project aligns with the Johns Hopkins Nursing Evidence-Based Practice (JHNEBP) model and organizational nursing support to improve patient outcomes (Dang \& Dearholt, 2018). Kotter's change model (1995) will guide the implementation of the project in the practice setting. The eight-step change model begins with establishing a sense of urgency to an opportunity and ends with sustaining the change by institutionalizing the new approaches (Kotter, 1995). These models were chosen because they are complementary to the implementation of evidence-based projects in the healthcare setting.

Kotter (1995) identified the first step to employ when attempting change is for the change team to identify why the change is needed and to communicate why the change is needed now. Change was needed in the organization because, in a four-month period, $67 \%$ of patients admitted to a medical-surgical unit experienced an HGE. The high rate of HGEs created a sense of urgency for a practice change. There were no previously documented QI efforts related to adherence to a hypoglycemia protocol, active surveillance of protocol outliers, or patient outcomes such as time from HGE to euglycemia. Usual care did not emphasize treating or reducing hypoglycemic events with a systematic best practice approach. Establishing, 
communicating with, and motivating a team to change hypoglycemia management proved to be critical to the success of the project.

\section{Evidence Search Strategy}

Key phrases and various combinations of key phrases were used to search for evidence related to the PICOT question. The PubMed database advanced search included English language, equivalent subjects, and looking within the full text of articles using specific keywords of hospitalized adults, hypoglycemia protocol, and decreased HGEs. This search produced 484 articles. The Google Scholar database was also searched using keyword combinations of hospitalized adults, medical-surgical, nurse-driven, adult, hypoglycemia protocol, nurse-driven protocol, hypoglycemia, HGEs, and decreased HGEs. This search resulted in 199 articles. The Cumulative Index of Nursing and Allied Health (CINAHL) Complete database was searched with the same criteria, which identified 52 articles. No date limits were used in any of the searches. Exclusion criteria included pediatrics, critical care, intensive care, peri-operative, insulin pump, continuous glucose monitoring, hyperkalemia treatment, diabetic ketoacidosis, gestational diabetes, intravenous insulin therapy, end of life, and any setting other than acute medical-surgical care. A search for systematic reviews related to hypoglycemia protocols in the English language was conducted in Google Scholar using keywords of systematic review and hypoglycemia protocols without results.

Content from the SHM, ADA, European Association for the Study of Diabetes (EASD), the Endocrine Society, American Association of Clinical Endocrinologists, the American Association of Diabetes Educators, American College of Endocrinology, the Canadian Diabetes Association, and the Joint British Diabetes Societies for Inpatient Care were also reviewed for consensus statements, practice standards, and clinical practice guidelines (CPG) related to nurse- 
driven hypoglycemia protocols. One standard and four guidelines were found to be current and relevant. In search of additional evidence, reference lists from the final 12 articles, consensus statements, practice, standards, and CPGs were reviewed, and seven quality improvement articles related to nurse involvement in hypoglycemia reduction were identified.

\section{Evidence Search Results and Evaluation}

All 735 article abstracts retrieved from PubMed, Google Scholar, and CINAHL Complete databases were screened for PICOT elements and 650 records were excluded. The remaining 65 full-text articles were assessed for applicability, and 53 were excluded when the population, setting, or intervention did not match the PICOT or when the articles did not represent research. A total of 12 primary research articles remained and were included in a PRISMA diagram (see Figure 1).

Primary research related to a nurse-driven hypoglycemia protocol on medical-surgical units is sparse. Only six studies have been published since 2015 (Abusamaan et al., 2019; Araque et al., 2018; Kadayakkara et al., 2019; Ndebu \& Colin, 2018; Pandey \& Chauhan, 2015; Maynard et al., 2015). The older six studies, from 1992 to 2014, are included in the evidence table as references because they were frequently cited by content experts. Each study was reviewed and assigned a level of evidence (see Table 1) using the patient-centered Strength of Recommendation Taxonomy (SORT) criteria (Ebell et al., 2004). Retrospective observational chart reviews for adherence to a nurse-driven hypoglycemia protocol, with a SORT level of 2, were performed in four of the studies (Abusamaan et al., 2019; Anthony, 2007; Coats \& Marshall, 2013; Gaston, 1992). Two studies focusing on nurse perceptions or knowledge related to hypoglycemia and treatment were given a SORT level of 3 (Engvall et al., 2014; Ndebu \& Colin 2018). Three studies had a retrospective pre- and postintervention design, SORT level 2, 
and focused on implementing or improving adherence to a nurse-driven hypoglycemia protocol (Araque et al., 2018; Hermayer et al, 2009; Kadayakkara et al., 2019). Maynard et al. (2008) conducted a retrospective, observational, matched case-control study, SORT level 2, involving 130 adults in attempts to identify risk factors resulting in a hypoglycemic event. Maynard et al. (2015) subsequently conducted a prospective observational study, SORT level 2, that instituted a hypoglycemia bundle and measured the HGEs and glycemic control. See Appendix A to review the evidence table for primary research including the SORT level assigned to each study.

Standards of care and clinical practice guidelines (CPG) were referenced in the literature as recommendations for best practice (AGREE Next Steps Consortium, 2017). The one standard of medical care for inpatient diabetes found in the search was published by the ADA (2020) and recommended the institution of a nurse-driven hospital-wide hypoglycemia protocol. These standards are reviewed and updated yearly.

Two CPGs were published by the Endocrine Society (LeRoith et al., 2019; Umpierrez et al., 2012). One related to the treatment of hyperglycemia and hypoglycemia in non-critical hospitalized patients (Umpierrez et al., 2012). The other developed recommendations for care of diabetes in older adults (LeRoith et al., 2019). The Canadian Diabetes Association CPG addressed adult hypoglycemia treatment in any setting (Yale et al., 2018). The one by the Joint British Diabetes Societies for Inpatient Care (JBDS-IP, 2020) specifically described the hospital management of hypoglycemia. Lastly, the Society of Hospital Medicine (2015) has published an implementation guide for initiating a glycemic control team in the hospital setting.

All standards and CPGs were assigned a SORT level of 3. Additional evidence, in the form of QI projects, was found during the literature search. Seven articles describing QI projects were identified as pertinent to the project and assigned a SORT level of 3. 


\section{Themes from the Evidence}

A synthesis of the findings from the literature review revealed that adherence to a nursedriven hypoglycemia protocol for adults hospitalized on non-critical units improved patient outcomes. Examples included time from HGE to euglycemia, HGEs rates, and HGE recurrence. The body of evidence had a SORT recommendation of C (see Figure 2) because it was based heavily on clinical practice guidelines and quality improvement practices. Themes included adherence to a hypoglycemia protocol, active surveillance and reporting, 15/15 rule, standardizing treatment and documentation, and educating about hypoglycemia risk factors.

\section{Adherence to a Hypoglycemia Protocol}

One theme identified from the primary research was significant nonadherence to the protocols established from CPGs and consensus statements. In one study, the time to repeat (TTR) blood glucose was only 14\% compliant with the 15 minutes outlined in the protocol (Abusamaan et al., 2019, p. 529). Anthony (2007) reported not one case of hypoglycemia, out of 210, had 100\% nurse compliance with a five-step hypoglycemia protocol (p. 713). Araque et al. (2018) detailed results of a study in which the median time from the HGE to euglycemia, after introduction of a protocol, decreased by 138 minutes and the time to repeat (TTR) was reduced from $76 \pm 14$ minutes to $28 \pm 10$ minutes (p.5). Coats et al. (2013) found that low adherence to a hypoglycemia protocol resulted in a 43.8\% recurrence of an HGE (p.19).

\section{Active Surveillance and Reporting}

Another theme recognized in the primary studies was that monitoring and reporting of compliance with HGE protocols improved outcomes. Four of the studies revealed that active surveillance by diabetes nurses and monitoring of adherence to the protocol were critical to improved HGE protocol adherence (Gaston, 1992; Maynard et al., 2008; Ndebu \& Colin, 2018; 
Pandey \& Chauhan, 2015). Maynard et al. (2015) noted significant reductions in hypoglycemic, severe hypoglycemic, and recurrent hypoglycemic days when, in addition to other measures, unit-specific reports were provided as feedback.

\section{5/15 Rule}

The primary themes identified in the CPGs (JBDS-IP, 2020; LeRoith et al., 2019; Umpierrez et al., 2012; Yale et al., 2018) and in the ADA (2020) standard of medical care were related to protocol recommendations. The primary recommendation was that for any blood glucose $<70 \mathrm{mg} / \mathrm{dL}$, the patient should receive 15 grams of carbohydrates followed by a repeat point of care (POC) blood glucose (BG) in 15 minutes (Umpierrez et al., 2012, p.32). The test/treat cycle should be repeated until the BG is $>80 \mathrm{mg} / \mathrm{dL}$. Alternate treatments were recommended for those patients who could not receive oral intake, but the test/repeat cycle would continue.

\section{Standardizing Treatment and Documentation}

Themes identified from the QI projects involved the need to standardize treatment, improve adherence to the protocol, increase documentation of the HGE and treatment, develop a method to identify the root cause, and evaluate data to recognize risks for recurrence. Four of the QI projects involved standardizing hypoglycemia and improving adherence to the hypoglycemia protocol (Destree et al., 2017; Maynard et al., 2015; Sleeman et al., 2018; Watts \& Nemes, 2018). The remaining three articles not only addressed the standard treatment of hypoglycemia through nurse-driven hypoglycemia protocols but also added a root cause or risk analysis factor to the protocol to prevent reoccurrence of hypoglycemia (Griffing, 2016; Milligan et al., 2015; Se \& Tucker, 2015).

\section{Educate to Risk}


A similar component in all of the QI projects to improve adherence was educating nurses about the pathophysiology of hypoglycemia, signs and symptoms, and the reasons behind each step in the protocol. A difference in one QI project that resulted in significant improvement in TTR outcomes was supplying the nursing staff with timers rather than having the nurse aide stay in the patient room to repeat the POC (Destree et al., 2017).

\section{Similarities and Differences}

Two similarities among the primary research studies listed in Appendix A were the setting and the population. All the studies were conducted in a hospital setting and all involved non-critical adult patients. Variances identified in the studies were related to the degree of hypoglycemia studied and the definition of hypoglycemia used in the measures. Four studies defined hypoglycemia as <70 mg/dL (Abusamaan et al., 2019; Anthony, 2007; Hermayer et al., 2009; Pandey \& Chauhan, 2015). Two defined hypoglycemia as $<4 \mathrm{mmol} / \mathrm{L}$ equivalent to 72 mg/dL (Coats \& Marshall, 2013; Ndebu \& Colin, 2018). Gaston (1992) used older criteria of $<80 \mathrm{mg} / \mathrm{dL}$. Three studies focused on severe hypoglycemia as opposed to standard hypoglycemia: Araque et al. (2007) and Kadayakkara et al. (2019) defined severe HGE as <50 mg/dL whereas Maynard et al. (2008) used $\leq 60 \mathrm{mg} / \mathrm{dL}$.

\section{Practice Recommendations}

The strength of recommendation based on the body of evidence, using the SORT criteria, was a $\mathrm{C}$ (see Figure 2). A strength of recommendation $\mathrm{C}$ indicates the body of evidence is patient-oriented but primary research is weak (Ebell et al., 2004). The physiological impact of hypoglycemia warrants a rapid response to correction (Araque et al., 2018). A nurse-led protocol sets treatment parameters that can be initiated as soon as possible to avoid delaying treatment while calling a provider for orders. The nature of the condition and need for rapid 
treatment do not support the use of randomized controlled trials to establish high-level evidence. Content experts have outlined the necessity of using a hypoglycemia protocol (ADA, 2020; JBDS-IP, 2020; LeRoith et al., 2019; SHM, 2015; Umpierrez et al., 2012; Yale et al., 2018). The primary research results from retrospective observational studies indicated a significant gap in adherence to best practice (Abusamaan et al., 2019; Anthony, 2007; Araque et al., 2018; Coats \& Marshall, 2013; Gaston, 1992; Kadayakkara et al., 2019; Maynard et al., 2008; Maynard et al., 2015; Ndebu \& Colin, 2018; Pandey \& Chauhan, 2015). Quality improvement projects have outlined interventions successful in increasing adherence (Destree et al., 2017; Griffing, 2016; Maynard et al., 2017; Milligan et al., 2015; Se \& Tucker, 2015; Watts \& Nemes, 2018). Therefore, after collectively reviewing the evidence, a practice recommendation for implementing an EBP active surveillance program to increase nurse adherence to an evidencebased hypoglycemia protocol for noncritical adults hospitalized in medical-surgical units, as opposed to usual care, was supported.

Monitoring adherence and providing active surveillance with feedback were recommended in the literature and were integrated into the project intervention at the unit level when the DCC was present. This project also included education related to the risks of untreated or undertreated hypoglycemia and a review of the current protocol that incorporated the $15 / 15$ rule (JBDS-IP, 2020; LeRoith et al., 2019; Umpierrez et al., 2012; Yale et al., 2018). Education was comprised of a step-by-step protocol review highlighting specific elements. Examples included 15 grams of carbohydrates available on the units, rechecking the BG 15 minutes after treatment with repeat cycles until the $\mathrm{BG}$ is $>80 \mathrm{mg} / \mathrm{dL}$, when to call the provider, and what to document. Lastly, nursing associates were provided metrics of protocol compliance through 
weekly reports on adherence. These reports were to increase the nursing associates' awareness of progress toward adherence and improved patient outcomes.

\section{Project Setting}

This project was conducted in a 237 bed, adult, level one trauma, and comprehensive stroke center in an urban area of Colorado. The hospital operates an air ambulance service and serves as a regional referral center that treats, on average, over 12,000 patients a year (Centura Health, n.d.-a). The hospital has four 36 bed medical-surgical units that specialize in trauma but also individually specialize in cardiology, neurology, oncology, and infectious disease. All 144 beds were included in the project. The typical medical-surgical patient is an adult with comorbid medical and trauma-related conditions. The hospital is part of a 17-hospital faith-based organization with the mission: "We extend the healing ministry of Christ by caring for those who are ill and by nurturing the health of the people in our communities" (Centura Health, n.d.-b). The vision is comprehensive in supporting all people to be whole and healthy (Centura Health, n.d.-b).

\section{Organizational Readiness}

Results from a strengths, weaknesses, opportunities, and threats (SWOT) analysis (see Appendix B) indicated organizational readiness for this project. Within the last year, improvement in DM management had become a hospital initiative. The endocrinology medical director solicited the support of the hospital executive team to increase efforts on improving diabetes inpatient services. A registered nurse DCC was hired with the primary goals of collecting data and coordinating the growth of a diabetes program.

Initial hypoglycemia data collection from EHR reviews, over three months, revealed that of 182 patients with a diagnosis of DM, 123 patients, or 67\%, had experienced an HGE during 
their medical-surgical unit stay. The estimated prevalence of inpatient hypoglycemia ranges from $3.5 \%$ to $45 \%$ (Cook et al., 2009, p. E7; Hulkower et al., 2014, p. 166). Additionally, during the same three-month time period, the time from the initial HGE to euglycemia was 122 minutes. Araque et al. (2018, p.5) had established an HGE to euglycemia benchmark of 87 minutes. Support from the executive team, the project's key stakeholders, was reaffirmed after the presentation of this performance gap. Other nursing organizational readiness indicators were

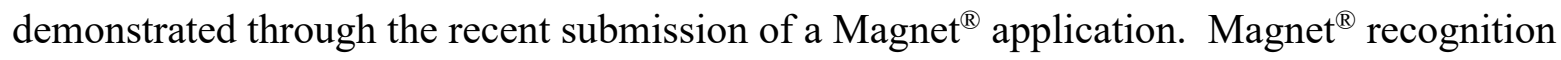
from the American Nurses Credentialing Center (ANCC, n.d.) is a prestigious nursing award. One criteria for Magnet ${ }^{\circledR}$ recognition is demonstrated nursing leadership alignment of nursing strategic goals to improved patient outcomes.

The mission of this project was to implement surveillance rounding with the intent to increase adherence to the hypoglycemia protocol and therefore improve patient outcomes. The vision was to execute this project with enthusiastic nursing engagement, which would spark a desire to pursue additional nurse-driven evidence-based practices in order to improve patient outcomes. This mission and vision supported the organization's mission to nurture whole and healthy patients.

\section{Project Overview}

This EBP project utilized a pre- and post-intervention approach. Specific objectives were based on the literature and involved increasing awareness of the negative patient consequences to undertreatment of hypoglycemia, initiating DCC surveillance rounding, improving nursing adherence to the hypoglycemia protocol, and decreasing the time from the initial HGE to euglycemia. The nursing awareness objective was measured using a pre- and post-education knowledge assessment (see Appendix F) through the organization's learning management system 
(LMS). The primary process measures were the percent of surveillance rounding completed by the DCC and of nursing adherence to all four steps of the protocol. Nursing adherence to the protocol was measured by the DCC performing a chart review of nursing documentation. Data collected by the DCC were reviewed by the DNP student for accuracy. The primary outcome measure for this project was the time from an initial HGE by POC to a BG value of $\geq 80 \mathrm{mg} / \mathrm{dL}$ also called euglycemia.

The population included any adult patient on the medical-surgical units with a documented HGE. Patient recruitment and consent were not required, as this was an EBP project and did not generate new knowledge. Patients with gestational diabetes, a primary diagnosis of DKA or HHS, or actively dying were excluded. Additional patient exclusions were those with provider orders not to treat the HGE (such as patients seen for palliative care or diagnostic tests), and those with less than four documented blood glucose values.

A risk assessment indicated a small number of low-level potential risks to accomplishing these objectives. They included nurse champion turnover, DCC performance concerns, scope creep, resistance to change from nursing, and delays or impediments to data collection.

Mitigation strategies, such as creating a sense of urgency and the provision of education related to the evidence supporting the intervention, were used to reduce resistance to change. Additional strategies addressed potential champion turnover. These included attempts to recruit more than one nurse and nurse aide champion per unit. Weekly IDT meetings to monitor and address scope creep and performance were scheduled to mitigate the derailment of project success. Unplanned budget constraints were not considered a risk, as existing resources were used for implementation and no additional financial support was required.

\section{Project Plan (Method)}


The JHNEBP model (Dang \& Dearholt, 2018) was used as a framework for the development of this project. Dang and Dearholt described the model (see Figure 3) as a threestep process that begins with inquiry. The authors explained that inquiry leads to the formation of a practice question, followed by a search for evidence addressing that question, and results from that evidence are then used to support a practice change. The process has also been called the PET process: Practice question, evidence, and translation (Dang \& Dearholt, 2018).

\section{Practice Question}

The practice problem (Dang \& Dearholt, 2018) was defined as nonadherence to the hypoglycemia protocol. The PICOT question was constructed to further guide the EBP process: In non-critical hospitalized adult patients on medical-surgical units with documented HGEs, how does active surveillance for strict adherence to a nurse-driven hypoglycemia protocol, compared to no surveillance, affect the time from hypoglycemia to euglycemia? A diabetes IDT had already been established, and additional stakeholders were identified. The DNP student was designated as the project lead and an integral member of the diabetes IDT.

\section{Evidence}

Components of the PICOT question were used to search the literature for evidence (Dang \& Dearholt, 2018). Primary research, consensus statements, CPGs, and QI were appraised and assigned SORT levels. The evidence was summarized and synthesized for overall strength. It was then determined that the evidence was good, with consistent results supporting education, active surveillance, and ongoing monitoring of protocol adherence.

\section{Translation}

The organization was assessed as a good fit and appropriate for translating the evidence into practice (Dang \& Dearholt, 2018). The executive team granted its support for 
implementation. The DNP student developed an action plan that included nursing education, active surveillance with feedback on performance, and ongoing reporting of adherence to the process and outcome measures. After the project received the organization and University IRB approval, the student, in collaboration with the IDT, implemented the intervention. Then, she evaluated the data based on defined outcomes. Although benchmarking was available for purchase through the SHM, the hospital in which this project was conducted did not subscribe to that service. Benchmarks for the variables in the project were set based on available primary studies, QI projects, and clinical practice guidelines (see Appendix G).

\section{Contextual Measures}

Contextual factors related to increased risk of experiencing a hypoglycemia event include age (Araque et al., 2018), biological gender (Araque et al., 2018), and diagnosis (ADA, 2020; Chandran et al., 2018). The diagnoses specifically measured for context were Type 1, Type 2 , pre-DM, or no diagnosis of DM. According to Araque et al. (2018) individuals greater than 60 years of age, without gender dominance, were more likely to have an HGE while hospitalized (p.4). Identifying those patients without a diagnosis of DM aligned with the ADA 2020 standards which stated that any patient, regardless of diagnosis, could experience an HGE (ADA, 2020). Chandran et al. (2018) determined that patients with Type 1 DM were at a significantly higher risk of an HGE than were patients with Type 2 DM (p.1).

\section{Nursing Education}

The DNP student provided education, through the LMS. She described the signs and symptoms of hypoglycemia, the physiological effects of hypoglycemia, the risks for hypoglycemia, and the hypoglycemia protocol (see Appendix E). Only the registered nurses regularly assigned to the medical-surgical units were given the education. A hypoglycemia 
management pocket card was placed in every patient room and offered to nurses working on the units (see Figure 4). Huddle tip sheets were distributed to the nurse and nurse aide champions to review with their teams during the change of shift huddle (see Figure 5). The project data collection start and end dates were announced and communicated to the units and key stakeholders.

Benchmarking for nursing knowledge related to diabetes is not readily available in the literature. Ndebu and Jones (2018) administered a questionnaire to nurses after participation in diabetes education. The authors did not reference the administration of a pre-test and therefore did not report a Delta score. Engvall et al. (2014) conducted a pre- and post-test design diabetes nursing knowledge study using the Diabetes Basic Knowledge Test (DBKT) and the Diabetes Self-Report Test (DSRT). The authors reported poor participation in the post-test and were therefore unable to make valid comparisons of the results. Neither the DBKT and the DSRT have proven to be consistently valid or reliable (Francisco, 2013).

\section{Active Surveillance}

The primary process measure in this project was the percentage of active surveillance rounds the DCC performed during the intervention period. When present on weekdays, the DCC ran a report from the EHR of HGEs. The DCC performed a chart review for adherence to the protocol and rounded on each unit to discuss performance with the nurses and nurse aides on duty. Hypoglycemia change champions, including nurses and nurse aides, were recruited from each unit. After participating in additional training at a project kickoff meeting, the champions provided real-time feedback to the nursing teams on the units. The champions also served as a protocol resource and were furnished with weekly project updates to share at the change of shift 
huddles. The DNP student met with the DCC and resolved any data inconsistencies, protocol concerns, or other challenges.

There was no benchmark provided in the literature for frequency of DCC surveillance rounding. Therefore, from an organizational baseline of zero, the implementation goal was for the DCC to round on $90 \%$ of the patients that had experienced an HGE.

\section{Hypoglycemia Protocol Adherence}

A secondary process measure was whether or not the nurse adhered to all four steps of the existing hypoglycemia protocol. The first step was BG measurement every 15 minutes from the initial HGE until euglycemia was reached. If the BG was measured between 15 and 30 minutes, then this step was considered compliant. The second protocol step was licensed independent practitioner (LIP) notification if a second treatment was required before a return to euglycemia. The third step was for the DCC to evaluate whether or not the nurse administered the appropriate treatment based on the patient's signs and symptoms and the BG value. The final protocol step was for the nurse to document the HGE. Documentation requirements included noting the patient's BG value, signs and symptoms, treatment provided, LIP notification if needed, and return to euglycemia. Protocol treatment orders are depicted in Figure 4.

A benchmark of $84 \%$ protocol adherence was chosen based on work by Destree et al. (2017, p.199). The authors conducted a quality improvement project related to adherence to a nurse-driven hypoglycemia protocol. They described a 38\% protocol adherence pre-intervention and a significant increase to $84 \%$ protocol adherence post-intervention.

\section{Outcome Measure}

The clinical outcome measure was the time it takes for the patient's BG to return to euglycemia after the HGE. All HGEs were included, regardless of the number of HGEs a patient 
had within a 24-hour period. Araque et al. (2018) studied the median time from HGE to euglycemia. The authors noted a pre-protocol intervention time from HGE to euglycemia of 225 minutes and a post-protocol intervention time of 87 minutes (Araque et al., 2018, p. 5). For benchmarking purposes, 87 minutes was used.

\section{Balancing Measure}

The percentage of hyperglycemia events per POC was monitored as a balancing measure while attention was drawn to the hypoglycemia protocol. Hospital hyperglycemia rates for noncritical patients have been measured at 31.7\% (Cook et al., 2009, p. E9). The facility in which this project took place, had an average $28 \%$ baseline of hyperglycemia events within a fourmonth period in 2020. The goal was to remain equal to or less than the baseline.

\section{Financial Measures}

A potential cost savings monitored was a decreased LOS measured in hours. The postintervention decreased TTN was multiplied by the hourly room rate to translate the decrease in time to a financial measure. A deliberate effort was made to avoid financial risks; therefore, the project was developed using current and available facility resources including staying within productive time allotments for hypoglycemia education.

\section{Ongoing Monitoring}

The DNP student organized and reviewed the data collected by the DCC prior to report distribution and statistical analysis. The DCC updated each unit weekly with the process and outcome measures data reports. Weekly reports were also provided to the IDT and unit managers for review. Periodic IDT meetings were conducted to examine challenges identified to protocol adherence, nurse and nurse aide participation, data collection, and any other scope creep indicators. The timeline for the project can be seen in Appendix C. 


\section{Results}

Data were reviewed retrospectively by the DNP student using the data provided by the DCC through EHR chart review. The DCC used a data collection tool developed by the DNP student (see Appendix D). Pre-intervention data was collected for ten weeks immediately prior to the intervention start date. The collection of post-intervention data began after IRB approval and continued for ten weeks. The data was stored on a facility computer that was double password protected. Only the DCC and the IDT had access to the data associated with a unique patient identifier. All patient identifiers were removed from the data bank prior to analysis at the end of the project. The IDT met as needed to review the integrity of the data. If an HGE occurred without a return to normal BG, i.e., death or discharge, then that data was excluded. The exclusion of any additional extraneous data was determined by the IDT as needed.

\section{Testing for Significance}

Pre- and post-intervention summary statistics were calculated using Intellectus Statistics (2020) predictive analysis software. An alpha level of 0.05 was used to determine statistical significance; however, if the intervention increased adherence to the hypoglycemia protocol and decreased the time from HGE to euglycemia, then it was considered clinically significant.

\section{Descriptive Statistics}

Observed frequencies and percentages for gender and diagnosis pre- and postintervention are presented in Table 3. 


\section{Table 3}

Frequency Table for Gender and Diagnosis

\begin{tabular}{ccccc}
\hline & \multicolumn{2}{c}{ Pre-intervention } & \multicolumn{2}{c}{ Post-intervention } \\
\cline { 2 - 5 } Variable & $n$ & $\%$ & $n$ & \\
\hline Gender & 55 & & 150 & 63.56 \\
Male & 57 & 59.11 & 86 & 36.44 \\
Female & 32 & & & \\
Diagnosis & 70 & 28.57 & 60 & 25.42 \\
None & 7 & 62.50 & 136 & 57.63 \\
Type 2 & 3 & 6.25 & 39 & 16.53 \\
Type 1 & 2.68 & 1 & .42 \\
Pre & 70.59 & \\
\hline
\end{tabular}

Note. Due to rounding errors, percentages may not equal $100 \%$.

The pre-intervention observation for age had an average of $64.81(S D=14.27)$ and the post-intervention was $64.44(S D=16.07)$. Post-intervention analysis reflected the DCC performed surveillance on $53.14 \%$ of patients who experienced an HGE.

The balancing measure post-intervention hyperglycemia frequency was calculated at $33 \%$ compared to the baseline of $28 \%$. The LOS hour change in pre- and post-intervention from HGE to TTN equated to a .51 -hour decrease. The .51 hour was multiplied by the hourly room rate of $\$ 93.38$ resulting in a $\$ 47.62$ savings.

\section{Inferential Statistics}

Nursing knowledge was evaluated by conducting a two-tailed Wilcoxon Signed Rank Test (Intellectus Software, 2020) examining the mean difference of the pre-test $M d n=70.00$ and 
post-test $M d n=100.00$ scores. The results of the two-tailed Wilcoxon signed rank test were based on an alpha value of $0.05, V=60.00, z=-11.21, p<.001$.

A Chi-square Test of Independence (Intellectus Software, 2020) was conducted to examine whether the pre- and post-intervention group's total hypoglycemia protocol adherence were independent (see Table 4).

\section{Table 4}

Observed and Expected Frequencies Hypoglycemia Protocol Adherence

\begin{tabular}{lcrrrr}
\hline & \multicolumn{2}{c}{ Total Compliance } & & & \\
\cline { 2 - 5 } Group & Yes & No & $\chi^{2}$ & $d f$ & $p$ \\
\hline Pre & $6[10.62]$ & $106[101.38]$ & 3.27 & 1 & .070 \\
Post & $27[22.38]$ & $209[213.62]$ & & & \\
\hline
\end{tabular}

Note. Values formatted as Observed[Expected].

A two-tailed Mann-Whitney $U$ test (Intellectus Software, 2020) was conducted to examine whether there were significant differences in TTN between the pre- and postintervention groups (see Table 5).

\section{Table 5}

Two-Tailed Mann-Whitney Test for TTN by Group

\begin{tabular}{|c|c|c|c|c|c|}
\hline \multirow[b]{2}{*}{ Variable } & \multicolumn{2}{|c|}{ Mean Rank } & \multirow[b]{2}{*}{$U$} & \multirow[b]{2}{*}{$z$} & \multirow[b]{2}{*}{$p$} \\
\hline & Pre & Post & & & \\
\hline TTN & 185.63 & 169.22 & 14463.00 & -1.42 & .155 \\
\hline
\end{tabular}


When compared to benchmarks in the literature, the project achieved both statistically and clinically significant results. Descriptive statistics indicated demographically male patients and patients with Type 2 DM were more likely to experience an HGE. This indicates that all patients, regardless of gender or diagnosis, should be considered vulnerable to experiencing an HGE. A statistically significance improvement was noted in levels of nurses' knowledge between the pre-and post-test. With an alpha set at 0.05 , statistical significance was not met in total adherence to the protocol; however, the resultant $p$ value indicates a $93 \%$ chance the intervention contributed to improvement. Similarly, there was an $85 \%$ chance that the TTN improvement was related to the DCC rounding.

Despite the following limitations, the project resulted in a 30-minute average decrease in TTN. Additionally, while statistical significance was not realized in the adherence to the protocol an improvement was noted.

\section{Limitations}

Time limitations for project implementation and the COVID-19 pandemic were two factors that affected the project's impact on practice change. The constraints of time resulted in the nurses' hypoglycemia education being offered at the same time, not previous to, data collection. The nurses were allotted the ten-week period throughout the project to complete the education, which resulted in more than $50 \%$ of completion occurring in the last two weeks. The DCC did not meet the percent of surveillance goal in part due to personal illness. Although feedback emails were sent to all nurses and nurse aides involved in the care of patients with an HGE detailing any outliers, this failed to equate with actively rounding.

The COVID-19 pandemic created multiple barriers to the implementation of the project. The pandemic substantially affected the availability of nursing personnel on the medical-surgical 
units. Staffing was augmented by outside staffing, float pool, and nurses without medicalsurgical expertise or hypoglycemia protocol education. The resulting alternate staffing models diverted focus away from the hypoglycemia protocol. The nurses and nurse aides consistently blamed their lack of adherence to the protocol on not having the time to recheck the BG within protocol standards.

The diabetes champions were unable to divert time away from the bedside to meet regularly for updates and support from the IDT. Multiple additional shifts were required for bedside care and all meetings were cancelled. Lastly, the informatics department significantly reduced nursing documentation by initiating a crisis navigator in the electronic medical record. The crisis navigator eliminated the hypoglycemia flow sheet as required documentation, which decreased the HGE documentation compliance and therefore overall protocol adherence.

\section{Next Steps}

Even though the projects interventions resulted in statistically and clinically significant improvements, continued efforts are needed to strengthen the nurses' protocol adherence. As COVID-19 cases continue to decline, the DCC increased active rounding. The medical-surgical units' nurse managers and clinical coordinators responsible for unit education refocused the nursing team on the treatment of hypoglycemia and the nurse-driven protocol. Each unit's shared governance council evaluated methods in which the team could collaborate in the treatment of an HGE. One example was to implement the use of timers placed outside a patient's room that would signal the need for a BG recheck. Another was to treat the HGE as a rapid response that was paged out to all the nurses on the unit where anyone available can contribute to treatment and monitoring.

\section{Sustainability}


To ensure improved adherence to the hypoglycemia protocol and treatment of HGEs continues, a standardized process involving the DCC performing EHR chart reviews and active surveillance through unit rounding was developed. Quarterly, data review of the time in minutes from HGE to euglycemia and the percentage of patients the DCC surveyed will be reported to the interdisciplinary quality and patient safety committee (QPSC). The QPSC members are the quality director, patient safety manager, data abstractor, infection preventionist, hospital executive leaders, and physicians.

\section{Plans for Dissemination}

Each medical-surgical unit was provided weekly updates regarding the progress of the project through written and verbal reports prepared by the DNP student. After the data was evaluated the DNP student shared the results with the participating units via a video conference town hall. The organization's QPSC was notified of the results in person, using a PowerPoint slideshow as a visual aide. The results will also be submitted to the corporate EBP council for a poster or podium presentation at the next annual EBP conference.

This manuscript will be published on the University of Saint Augustine for Health Sciences institutional scholarship and open access repository (SOAR). An abstract of the results will be submitted, for a podium or poster presentation, to the medical-surgical nursing conference hosted by the Academy of Medical-Surgical Nurses. A written manuscript will be submitted to the journal Diabetes Spectrum for publication consideration. All presentations, posters, and manuscripts will be peer-reviewed by Ph.D. or DNP prepared colleagues before submission or presentation.

\section{Conclusion}


The purpose of this project was to implement active surveillance by a DCC focused on adherence to a nurse-driven hypoglycemia protocol and the effects protocol adherence has on the time from an HGE to euglycemia. The significance of hypoglycemia in hospitalized medicalsurgical adults and a relevant PICOT question was identified. A literature search identified that poor adherence to a nurse-driven protocol was common. Evidence results and an evidence summary supporting an intervention involving nursing education, monitoring and reporting, and active surveillance to improve adherence and patient outcomes was described. The JHNEBP model was identified as a framework to guide the project development and an evaluation plan for analyzing the significance of the project data was outlined. The DCC rounding proved to be clinically significant as adherence to each component of the protocol improved, the time from HGE to euglycemia improved, and a statistically significant improvement in nursing knowledge related to the physiological effects of hypoglycemia and treatment was identified. Continued emphasis on nurses' adherence to the hypoglycemia protocol through DCC surveillance and additional innovative practices is necessary for improved patient outcomes. 


\section{References}

Abusamaan, M., Klonoff, D., \& Mathioudakis, N. (2019). Predictors of time-to-repeat of pointof-care glucose following hypoglycemic events in hospitalized patients. Journal of Diabetes Science and Technology, 14(3), 526-534.

https://www.doi.org/10.1177/1932296819883332

AGREE Next Steps Consortium. (2017). The AGREE II instrument [Electronic Version]. http://www.agreetrust.org

Aloi, J., Mulla, C., Ullal, J., \& Lieb, D. (2015). Improvement in inpatient glycemic care: Pathways to quality. Current Diabetes Reports, 15(18), 17-18. https://www.doi.org/10.1007/s11892-015-0587-4

American Diabetes Association. (2018). Economic costs of diabetes in the U.S. in 2017. Diabetes Care, 41, 917-928. https://www.doi.org/10.2337/dci18-0007

American Diabetes Association. (2020). Diabetes care in the hospital: Standards of medical care in diabetes-2020. Diabetes Care, 43(Supplement 1), S193-S202. https://www.doi.org/10.2337/dc20-S015

American Nurses Credentialing Center (n.d.). ANCC Magnet recognition program. https://www.nursingworld.org/organizational-programs/magnet/

Anthony, M. (2007). Treatment of hypoglycemia in hospitalized adults. The Diabetes Educator, 33(4), 709-715. https://www.doi.org/10.1177/0145721707303806

Araque, K., Kadayakkar, D., Gigauri, N., Sheehan, D., Majumdar, S., Buller, G., \& Flannery, C. (2018). Reducing severe hypoglycemia in hospitalized patients with diabetes: Early outcomes of standardized reporting and management. BMJ Open Access, 7(e000120), 17. https://www.doi.org/10.1136/bmjoq-2017-000120 
Bommer, C., Heesemann, E., Sagalova, V., Manne-Goehler, J., Atun, R., Bärnighausen, T., \& Vollmer, S. (2017). The global economic burden of diabetes in adults aged 20-79 years: A cost-of-illness study. The Lancet: Diabetes \& Endocrinology, 5(6), 423-430. https://www.doi.org/10.1016/S2213-8587(17)30097-9

Centers for Disease Control and Prevention, National Diabetes Prevention Program. (2020). National diabetes statistics report, 2020: Estimates of diabetes and its burden in the United States. https://www.cdc.gov/diabetes/pdfs/data/statistics/national-diabetesstatistics-report.pdf

Centers for Disease Control and Prevention. (2020, June 11). What is diabetes? https://www.cdc.gov/diabetes/basics/diabetes.html

Centura Health. (n.d.a). Award-winning care that heals, inspires \& connects. https://www.centura.org/locations/st-anthony-hospital/about

Centura Health. (n.d.b). Mission \& values. https://www.centura.org/about-centura/mission-andvalues

Chandran, S., Tay, W., Lye, W., Lim, L., Ratnasingam, J., Tan, A., \& Gardner, D. (2018). Beyond HbA1c: Comparing glycemic variability and glycemic indices in predicting hypoglycemia in Type 1 and Type 2 diabetes. Diabetes Technology \& Therapeutics, 20(5), 1-10. https://www.doi.org/10.1089/dia.2017.0388

Coats, A., \& Marshall, D. (2013). Inpatient hypoglycaemia: A study of nursing management. Nursing Praxis in New Zealand, 29(2), 15-24. https://pubmed.ncbi.nlm.nih.gov/24187806/ 
Conover, W. J., \& Iman, R. L. (1981). Rank transformations as a bridge between parametric and nonparametric statistics. The American Statistician, 35(3), 124-129. https://doi.org/10.1080/00031305.1981.10479327

Cook, C., Kongable, G., Potter, D., Abad, V., Leija, D., \& Anderson, M. (2009). Inpatient glucose control: A glycemic survey of 126 hospital. Journal of Hospital Medicine, 4(9), E7-E14. https://www.doi.org/10.1002/jhm.533

Cruz, P. (2020). Inpatient hypoglycemia: The challenge remains. Journal of Diabetes Science and Technology, 14(3), 560-566. https://www.doi.org/10.1177/1932296820918540

Dang, D., \& Dearholt, S. (2018). Johns Hopkins nursing evidence-based practice: Model and guidelines ( $3^{\text {rd }}$ ed.) [Kindle Book]. Dustin Sullivan. https://www.amazon.com

Destree, L., Vercellino, M., \& Armstrong, N. (2017). Interventions to improve adherence to a hypoglycemia protocol. Diabetes Spectrum, 30(3), 195-201. https://www.doi.org/10.2337/ds16-0042

Ebell, M., Siwek, J., Weiss, B., Woolf, S., Susman, J., Ewigman, B., \& Bowman, M. (2004). Strength of recommendation taxonomy (SORT): A patient-centered approach to grading evidence in the medical literature. American Family Physician, 69(3), 548-556. https://www.jabfm.org/content/jabfp/17/1/59.full.pdf

Engvall, J., Padula, C., Krajewski, A., Rourke, J., McGillivray, C., Desroches, S., \& Anger, W. (2014). Empowering the development of a nurse-driven protocol. Medsurg Nursing, 23(3), 149-154. http://www.medsurgnursing.net/cgi-bin/WebObjects/MSNJournal.woa Forouhi, N., \& Wareham, N. (2014). Epidemiology of diabetes. Medicine, 42(12), 698-702. https://www.doi.org/10.1016/j.mpmed.2014.09.007 
Francisco, M. (2013). Instruments that measure nurses' knowledge about diabetes: An integrative review. Journal of Nursing Measurement, 21(1), 137-152. https://www.doi.org/10.1891/1061-3749.21.1.137

Gaston, S. (1992). Outcomes of hypoglycemia treated by standardized protocol in a community hospital. The Diabetes Educator, 18(6), 491-494. https://doi.org/10.1177/014572179201800607

Griffing, K. (2016). Hypoglycemia prevention in hospital patients: A quality improvement project to prevent severe and recurrent hypoglycemia. Clinical Diabetes, 34(4), 193-199. https://www.doi.org/10.2337/cd15-0055

Hermayer, K., Cawley, P., Arnold, P., Sutton, A., Crudup, J., Kozlowski, L., Hushion, T., Sheakley, M., Epps, J., Weil, R., \& Carter, R. (2009). Impact of improvement efforts on glycemic control and hypoglycemia at a university medical center. Journal of Hospital Medicine, 4, 331-339. https://www.doi.org/10.1002/jhm.449

Hui, D., Nooruddin, Z., Didwaniya N., Dev, R., De La Cruz, M., Kim, S., Kwon, J., Hutchins, R., Liem, C., \& Bruera, E. (2014). Concepts and definitions for "actively dying," "end of life," "terminally ill," "terminal care," and "transitions of care": A systematic review. Journal of Pain and Symptom Management, 47(1), 77-89. https://www.doi.org/10.1016/j.jpainsymman.2013.02.021

Hulkower, R., Pollack, R., \& Zonszein, J. (2014). Understanding hypoglycemia in hospitalized patients. Diabetes Management, 4(2), 165-176. https://www.ncbi.nlm.nih.gov/pmc/articles/PMC4153389/

Intellectus Statistics [Online computer software]. (2020). Intellectus Statistics. https://analyze.intellectusstatistics.com/ 
Jefferson County Public Health Department (with Centura Health \& SCL Health). (2018). Jefferson County community health needs assessment: Diabetes. https://insight.livestories.com/s/v2/physical-health/36988cac-35e7-487b-96e8$\mathrm{a} 490 \mathrm{~b} 2 \mathrm{a} 85 \mathrm{a} 41$

Joint British Diabetes Societies for Inpatient Care. (2020). The hospital management of hypoglycaemia in adults with diabetes mellitus ( $\left.4^{\text {th }} \mathrm{ed}.\right)$. https://www.diabetes.org.uk/resources-s3/202001/JBDS $\% 20$ HypoGuideline $\% 204^{\text {tho }} \% 20$ edition $\% 20$ FINAL.pdf

Kadayakkara, D., Balasubramanian, P., Araque, K., Davis, K., Javed, F., \& Niaki, P. (2019). Multidisciplinary strategy to treat severe hypoglycemia in hospitalized patients with diabetes mellitus reduce inpatient mortality rate: Experience from an academic community hospital. PloS ONE, 14(8), 1-5. https://www.doi.org/10.1371/journal.pone.0220956

Kalra, S., Mukherjee, J., Venkataraman, S., Bantwal, G., Shaikh, S., Saboo, B., Das, A., \& Ramachandran, A. (2013). Hypoglycemia: The neglected complication. Indian Journal of Endocrinology and Metabolism, 17(5), 819-834. https://www.doi.org/10.4103/22308210.117219

Kim, D., Li, A., Cholankeril, G., Kim, S., Ingelsson, E., Knowles, W., Harrington, R., \& Ahmed, A. (2019). Trends in overall cardiovascular and cancer-related mortality among individuals with diabetes reported on death certificates in the United States between 2007 and 2017. Diabetologia, 62(7), 1185-1194. https://doi.org/10.1007/s00125-019-4870-9

Kotter, J. (1995). Leading change: Why transformation efforts fail. Harvard Business Review, 59-67. 
http://www.mcrhrdi.gov.in/91fc/coursematerial/management/20\%20Leading\%20Change $\% 20-\% 20$ Why $\% 20$ Transformation $\% 20$ Efforts $\% 20$ Fail $\% 20$ by $\% 20 J P \% 20$ Kotter.pdf

LiRoith, D., Biessels, G., Braithwaite, S., Casanueva, F., Draznin, B., Halter, J., Hirsch, I., McDonnell, M., Molitch, M., Murad, M., \& Sinclair, A. (2019). Treatment of diabetes in older adults: An Endocrine Society clinical practice guideline. Journal of Clinical Endocrinology \& Metabolism, 104(5), 1520-1574. https:/www.doi.org/10.1210/jc.201900198

Mandel, S., Langan, S., Mathioudakis, N., Sidhaye, A., Bashura, H., Bie, J., Mackay, P., Tucker, C., Demidowich, A., Simonds, W., Jha, S., Ebenuwa, I., Kantsiper, M., Howell, E., Wachter, P., Golden S., \& Zilbermint, M. (2019). Retrospective study of inpatient diabetes management service, length of stay and 30-day readmission rate of patients with diabetes at a community hospital. Journal of Community Hospital Internal Medicine Perspectives, 9(2), 64-73. https://www.doi.org/10.1080/20009666.2019.1593782

Maynard, G., Huynh, M., \& Renall, M. (2008). Iatrogenic inpatient hypoglycemia: Risk factors, treatment, and prevention: Analysis of current practice at an academic medical center with implications for improvement efforts. Diabetes Spectrum, 21(4), 241-247. https://spectrum.diabetesjournals.org/content/21/4/241

Maynard, G., Kulasa, K., Ramos, P., Childers, D., Clay, B., Sebasky, M., Fink, E., Field, A., Renvall, M., Juang, P., Choe, C., Pearson, D., Serences, B., \& Lohnes, S. (2015). Impact of a hypoglycemia reduction bundle and a systems approach to inpatient glycemic management. Endocrine Practice, 21(1), 355-367. https://www.doi.org/10.4158/EP14367.OR 
McHugh, M. L. (2013). The chi-square test of independence. Biochemia Medica, 23(2), 143-149. https://doi.org/10.11613/BM.2013.018

Milligan, P., Bocos, M., Pratt, E., Howhner, C., Krettek, J., \& Dunagan, W. (2015). Multifaceted approach to reducing occurrence of severe hypoglycemia in a large healthcare system. American Journal of Health-System Pharmacy, 72, 1631-1641. https://www.doi.org/10.2146/ajhp150077

Moher, D., Liberati, A., Tetzlaff, J., \& Altman, D. (2009). Preferred reporting items for systematic reviews and meta-analyses: The PRISMA statement. PLoS Med 6(7), e1000097. https://www.doi.org/10.1371/journal.pmed.1000097

Ndebu, J., \& Colin, J. (2018). Inpatient nursing staff knowledge on hypoglycaemia management. Journal of Diabetes Nursing, 22(1), 24-28. https://www.diabetesonthenet.com/journal/journal-of-diabetes-nursing

Pandey, S., Chauhan, A. (2015). Achieving 100\% reporting of hypoglycemia in a tertiary care hospital through a structured action pathway \& persistent monitoring tool among nurses. International Journal of Nursing Education, 7(2), 111-115. https://www.doi.org/10.5958/0974-9357.2015.00085.9

Razali, N. M., \& Wah, Y. B. (2011). Power comparisons of Shapiro-Wilk, KolmogorovSmirnov, Lilliefors and Anderson-Darling tests. Journal of Statistical Modeling and Analytics, 2(1), 21-33.

Robbins, T., Keung, S., Sankar, S., Randeva, H., \& Arvanitis, T. (2019). Risk factors for readmission of inpatients with diabetes: A systematic review. Journal of Diabetes and Its Complications, 33, 398-405. https://www.doi.org/10.1016/j.jdiacomp.2019.01.004 
Se, S., \& Tucker, K. (2015). Hypoglycemia prevention: An innovative approach. Nursing2015, 45(6), 19-22. https://www.doi.org/10.1097/01.NURSE.0000464993.71477.b0

Sleeman, K., Davis, A., \& Veall, A. (2018). Pilot study of a hypoglycaemia care bundle label. Journal of Diabetes Nursing, 22(3), 1-5.

https://www.diabetesonthenet.com/journal/journal-of-diabetes-nursing

Society of Hospital Medicine [SHM]. (2015). The glycemic control implementation guide:

Improving glycemic control, preventing hypoglycemia and optimizing care of the inpatient with hyperglycemia and diabetes.

https://shm.hospitalmedicine.org/acton/media/25526/download-shms-glycemiccontrol-guide

Speroni, K., McLaughlin, M., \& Friesen, M. (2020). Use of evidence-based practice models and research findings in magnet-designated hospitals across the United States: National survey results. Worldviews on Evidence-Based Nursing, 17(2), 98-107. https://doi.org/10.1111/wvn.12428

Umpierrez, G., Hellman, R., Korytkowski, M., Kosiborod, M., Maynard, G., Montori, V., Seley, J., \& Van den Berghe, G. (2012). Management of hyperglycemia in hospitalized patients in non-critical care setting: An Endocrine Society clinical practice guideline. Journal of Clinical Endocrinology \& Metabolism, 97(1), 16-38.

https://www.doi.org/10.1210/jc.2011-2098

U.S. Department of Health and Human Services. (2019, October 21). National action plan for ADE prevention. https://health.gov/our-work/health-care-quality/adverse-drugevents/national-ade-action-plan 
Watts, S., \& Nemes, D. (2018). Best practice nursing management of nosocomial hypoglycemia: Lessons learned. Medsurg Nursing, 27(2), 98-102. http://www.medsurgnursing.net/cgibin/WebObjects/MSNJournal.woa

Westfall, P. H., \& Henning, K. S. S. (2013). Texts in statistical science: Understanding advanced statistical methods. Taylor \& Francis.

White, K., Dudley-Brown, S., \& Terhaar, M. (2016). Translation of evidence into nursing and health care ( $2^{\text {nd }}$ ed.) [Kindle Book]. Springer. https://www.amazon.com

Winterstein, A., Jeon, M., Staley, B., Xu, D., Henriksen, C., \& Pflugfelder, G. (2018). Development and validation of an automated algorithm for identifying patients at high risk for drug-induced hypoglycemia. American Journal of Health-System Pharmacy, 75(21), 1714-1728. https://www.doi.org/10.2146/ajhp180071

World Health Organization. (2018). Diabetes. https://www.who.int/news-room/factsheets/detail/diabetes

Yale, J., Paty, B., \& Senior, P. (2018). Hypoglycemia: 2018 clinical practice guidelines. Canadian Journal of Diabetes, 42, S104-S108. https://www.doi.org/10.1016/j.jcjd.2017.10.010 
Figure 1

PRISMA Diagram of Literature Search
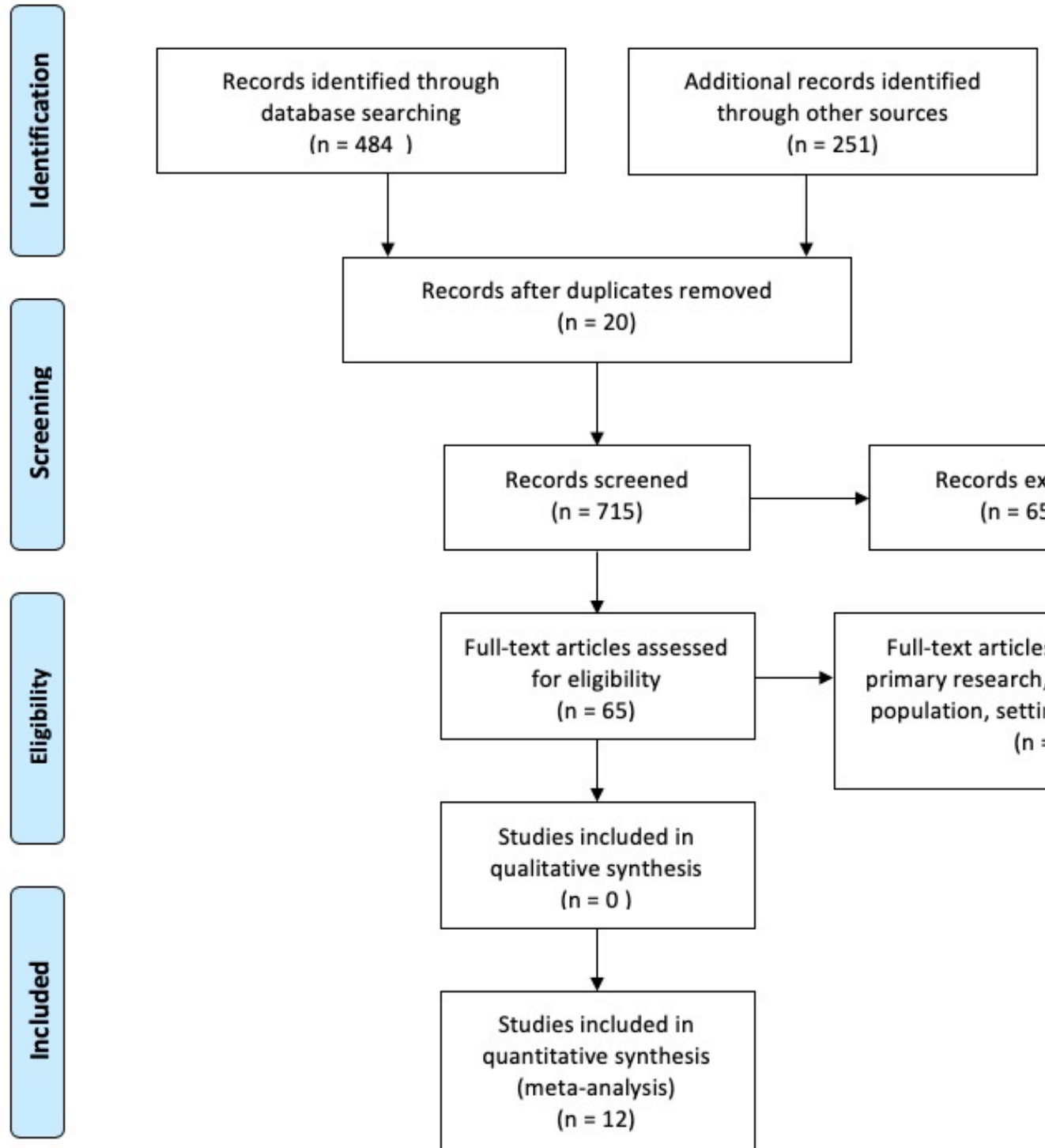

$(n=484)$
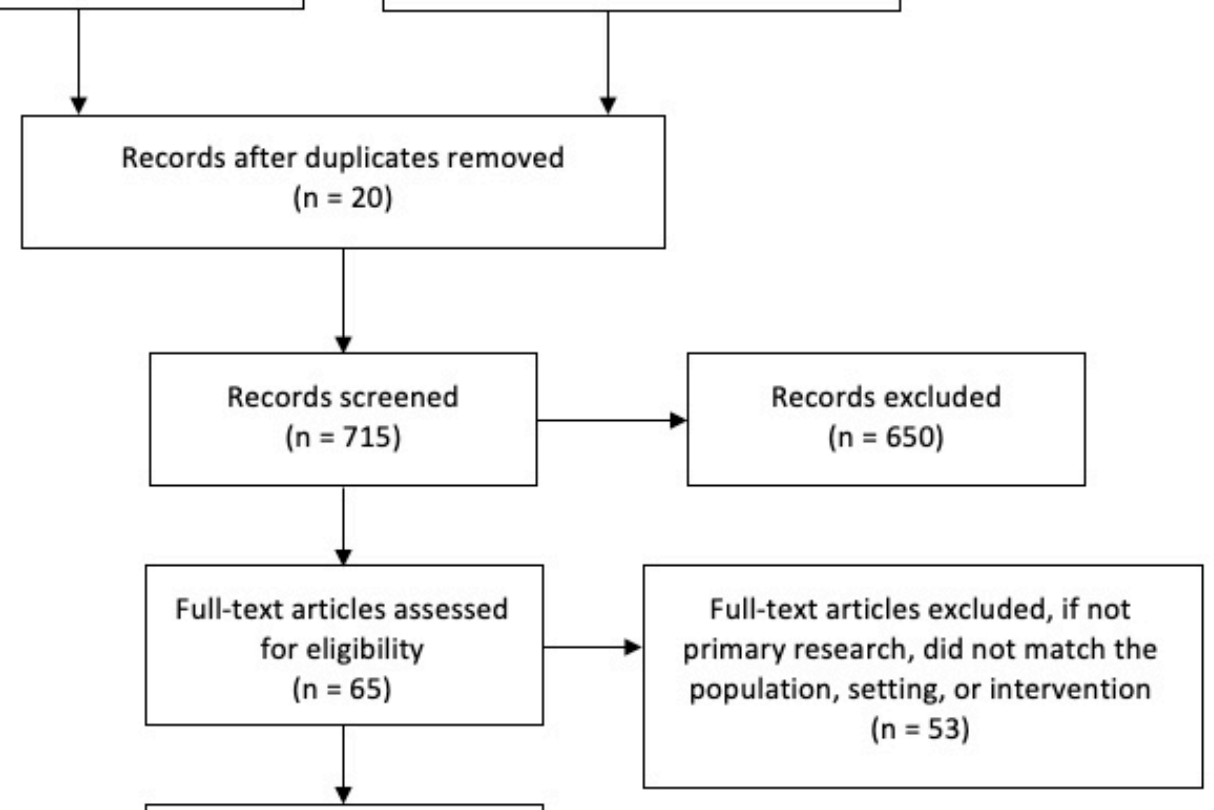

Studies included in

qualitative synthesis

$(n=0)$

뭠

Studies included in

quantitative synthesis

(meta-analysis)

$(n=12)$

Note. Moher, et al. (2009) 
Table 1

Strength of Recommendation Taxonomy (SORT) Level Definitions

\begin{tabular}{|c|c|c|c|}
\hline Study quality & Diagnosis & $\begin{array}{c}\text { Treatment/Prevention/ } \\
\text { Screening }\end{array}$ & Prognosis \\
\hline \multirow[t]{3}{*}{$\begin{array}{l}\text { Level } 1-\text { good- } \\
\text { quality patient- } \\
\text { oriented evidence }\end{array}$} & $\begin{array}{l}\text { Validated clinical } \\
\text { decision rule }\end{array}$ & $\begin{array}{l}\mathrm{SR} / \text { meta-analysis of } \\
\mathrm{RCT} \text { s with consistent } \\
\text { findings }\end{array}$ & $\begin{array}{l}\text { SR/meta-analysis of good- } \\
\text { quality cohort studies }\end{array}$ \\
\hline & $\begin{array}{l}\text { SR/meta-analysis } \\
\text { of lower-quality } \\
\text { studies or studies } \\
\text { with inconsistent } \\
\text { findings }\end{array}$ & $\begin{array}{l}\text { High-quality individual } \\
\text { RCT } \\
\text { All-or-none study }\end{array}$ & $\begin{array}{l}\text { Prospective cohort study } \\
\text { with good follow-up }\end{array}$ \\
\hline & $\begin{array}{l}\text { Lower-quality } \\
\text { diagnostic cohort } \\
\text { study or diagnostic } \\
\text { case-control study }\end{array}$ & & \\
\hline \multirow[t]{4}{*}{$\begin{array}{l}\text { Level } 2 \text {-limited- } \\
\text { quality patient- } \\
\text { oriented evidence }\end{array}$} & $\begin{array}{l}\text { Unvalidated } \\
\text { clinical decision } \\
\text { rule }\end{array}$ & $\begin{array}{l}\mathrm{SR} / \text { meta-analysis of } \\
\text { lower-quality clinical } \\
\text { trials or of studies with } \\
\text { inconsistent findings }\end{array}$ & $\begin{array}{l}\mathrm{SR} / \text { meta-analysis of lower- } \\
\text { quality cohort studies or } \\
\text { with inconsistent results }\end{array}$ \\
\hline & $\begin{array}{l}\text { SR/meta-analysis } \\
\text { of lower-quality } \\
\text { studies or studies } \\
\text { with inconsistent }\end{array}$ & $\begin{array}{l}\text { Lower-quality clinical } \\
\text { trial }\end{array}$ & $\begin{array}{l}\text { Retrospective cohort study } \\
\text { or prospective cohort study } \\
\text { with poor follow-up }\end{array}$ \\
\hline & finding & Cohort study & Case-control study \\
\hline & $\begin{array}{l}\text { Lower-quality } \\
\text { diagnostic cohort } \\
\text { study or diagnostic } \\
\text { case-control study }\end{array}$ & Case-control study & Case series \\
\hline $\begin{array}{l}\text { Level 3-other } \\
\text { evidence }\end{array}$ & \multicolumn{3}{|c|}{$\begin{array}{l}\text { Consensus guidelines, extrapolations from bench research, usual practice, } \\
\text { opinion, disease-oriented evidence (intermediate or physiologic outcomes } \\
\text { only), or case series for studies of diagnosis, treatment, prevention, or } \\
\text { screening }\end{array}$} \\
\hline
\end{tabular}

Note. $\mathrm{SR}=$ systematic review; $\mathrm{RCT}=$ randomized controlled trial 


\section{Figure 2}

Strength of Recommendation Based on a Body of Evidence Algorithm

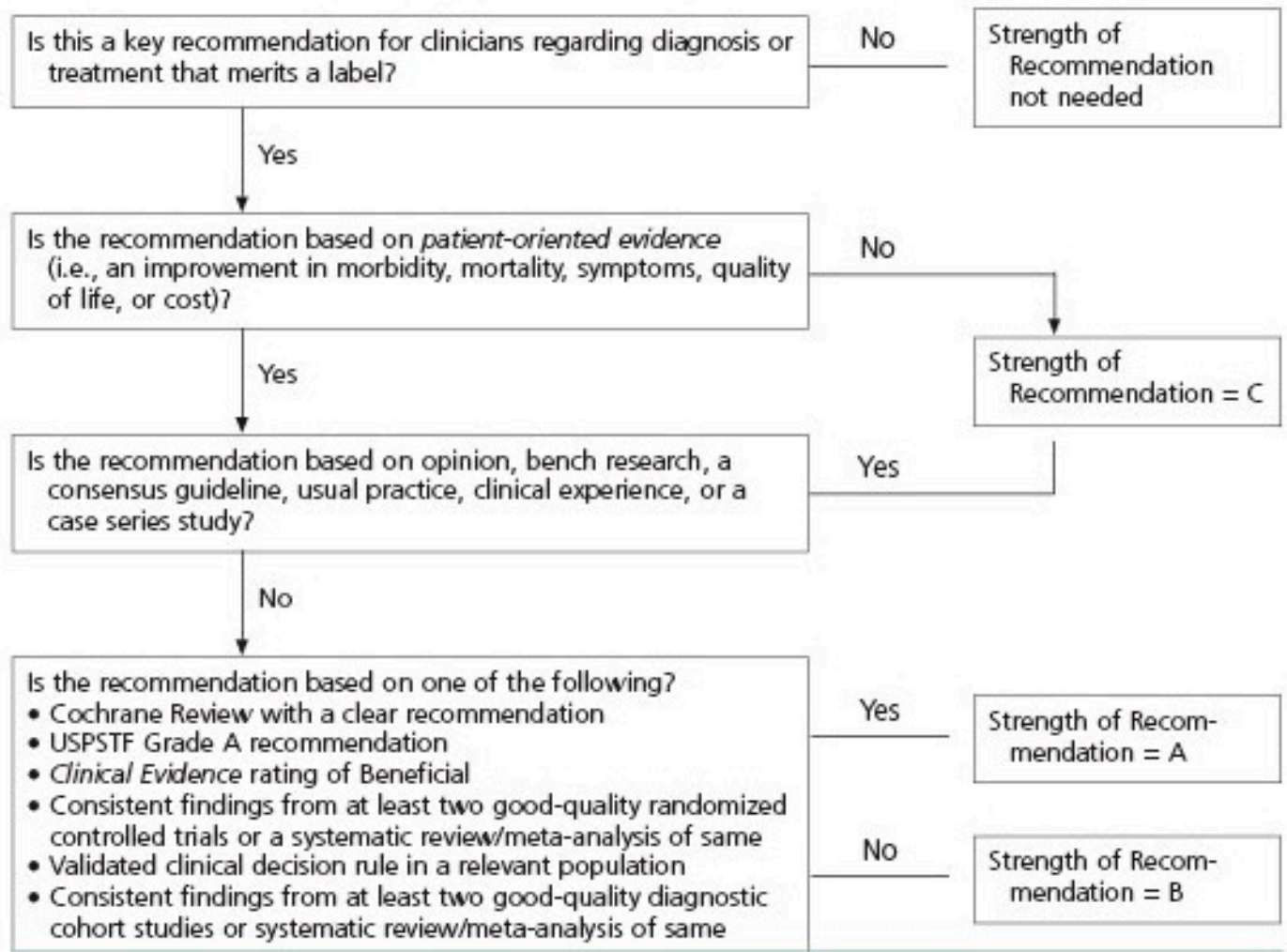


Figure 3

JHNEBO Model

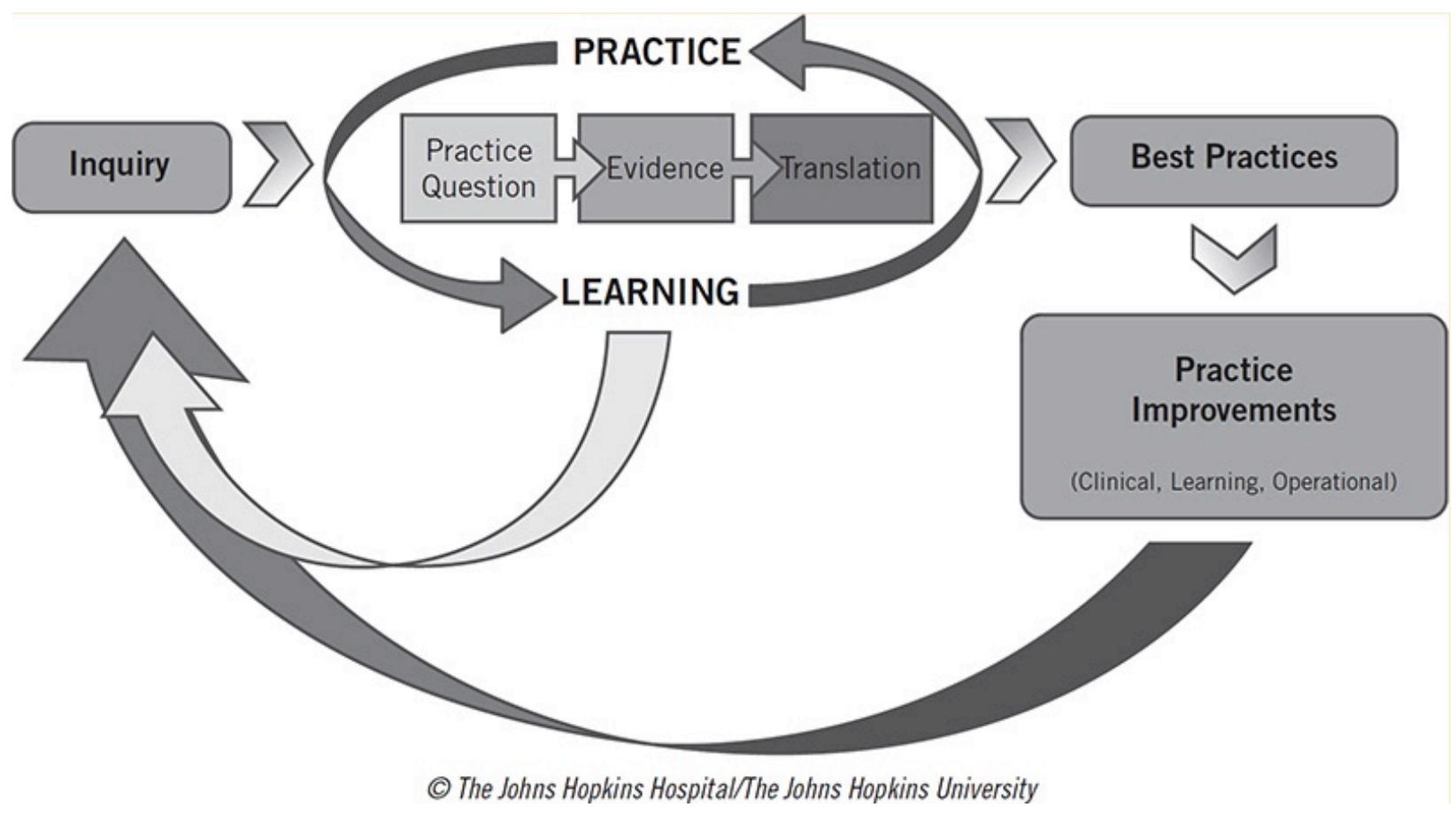


Figure 4

\section{Hypoglycemia Management Pocket Card}

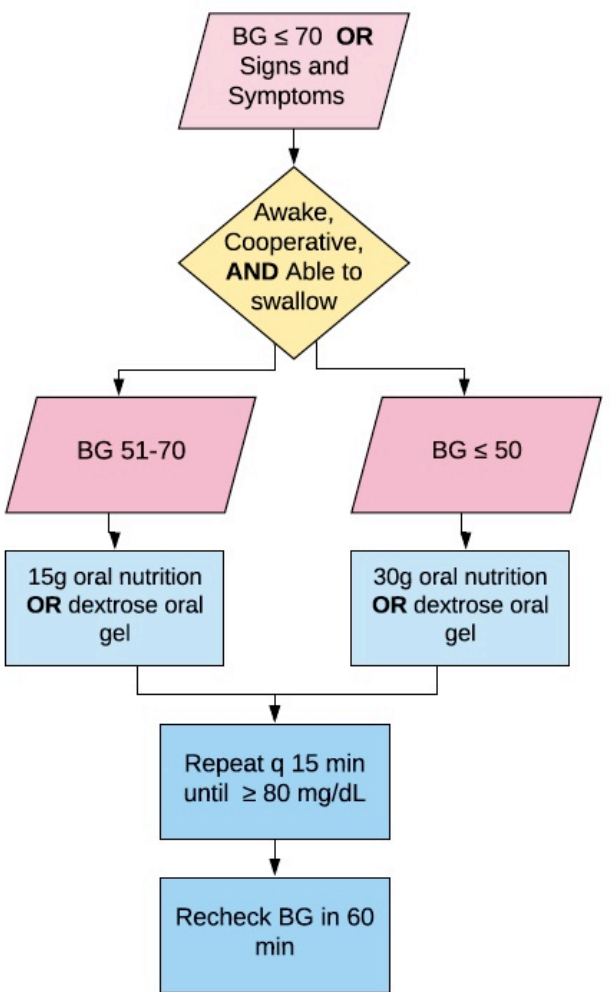

Hypoglycemia Management Precose/Arabose--DO NOT give table sugar Renal diet--DO NOT give milk, orange juice, colas, cheese, or peanut butter Fluid Restriction--use glucose gel, table sugar, or jelly packet NOTIFY LIP after 2nd intervention if BG not $\geq 80 \mathrm{mg} / \mathrm{dL}$. Document the event

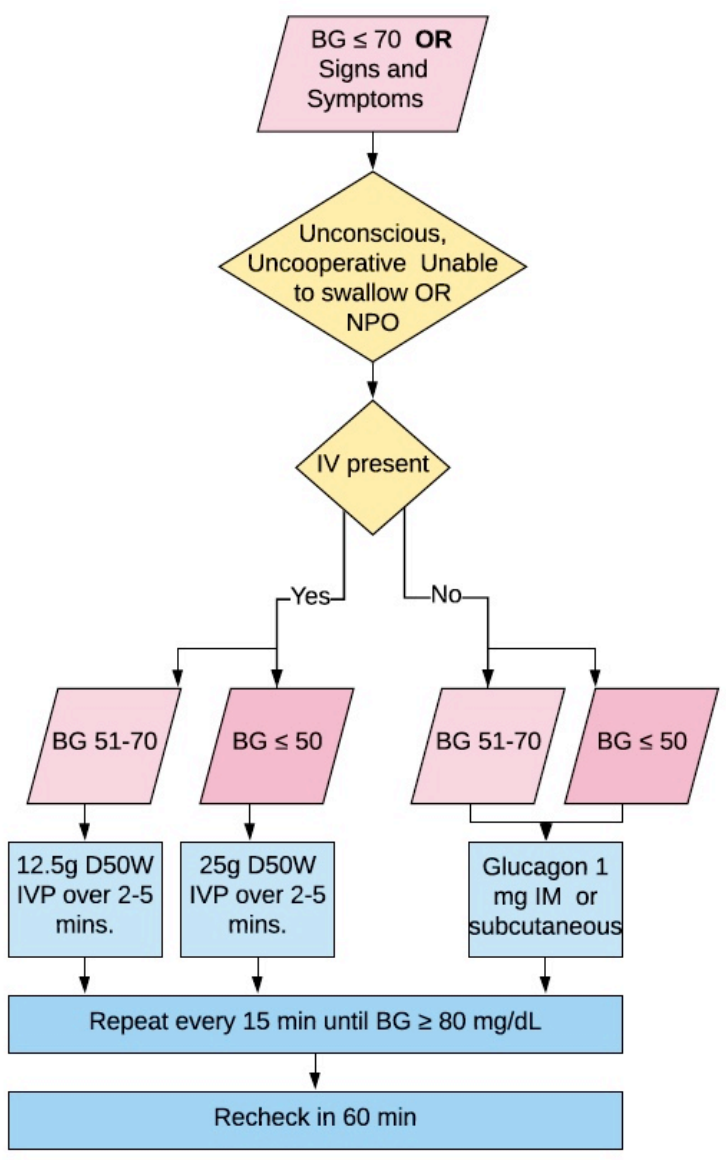




\section{Figure 5}

\section{Huddle Flier}

\section{Huddle Sheet: Hypoglycemia Protocol}

Between $20-25 \%$ of patients will experience a hypoglycemic event during hospitalization

Initiate on any patient with signs and symptoms of hypoglycemia or with $B G \leq 70 \mathrm{mg} / \mathrm{dL}$

Recheck BG 15-30min. Repeat until BG $\geq 80 \mathrm{mg} / \mathrm{dL}$

Check BG 60 minutes after reaching $B G \geq 80 \mathrm{mg} / \mathrm{dL}$

Notify LIP after $\mathbf{2}$ interventions or change in patient condition

Document event:

- Hypoglycemia flowsheet

- Include BG, s/sx, conscious/unconscious, LIP, treatment

- Always reassess patient and document

** It is the PCA responsibility to notify RN of low BG value. It is RN's responsibility treat, re-assess, and document**
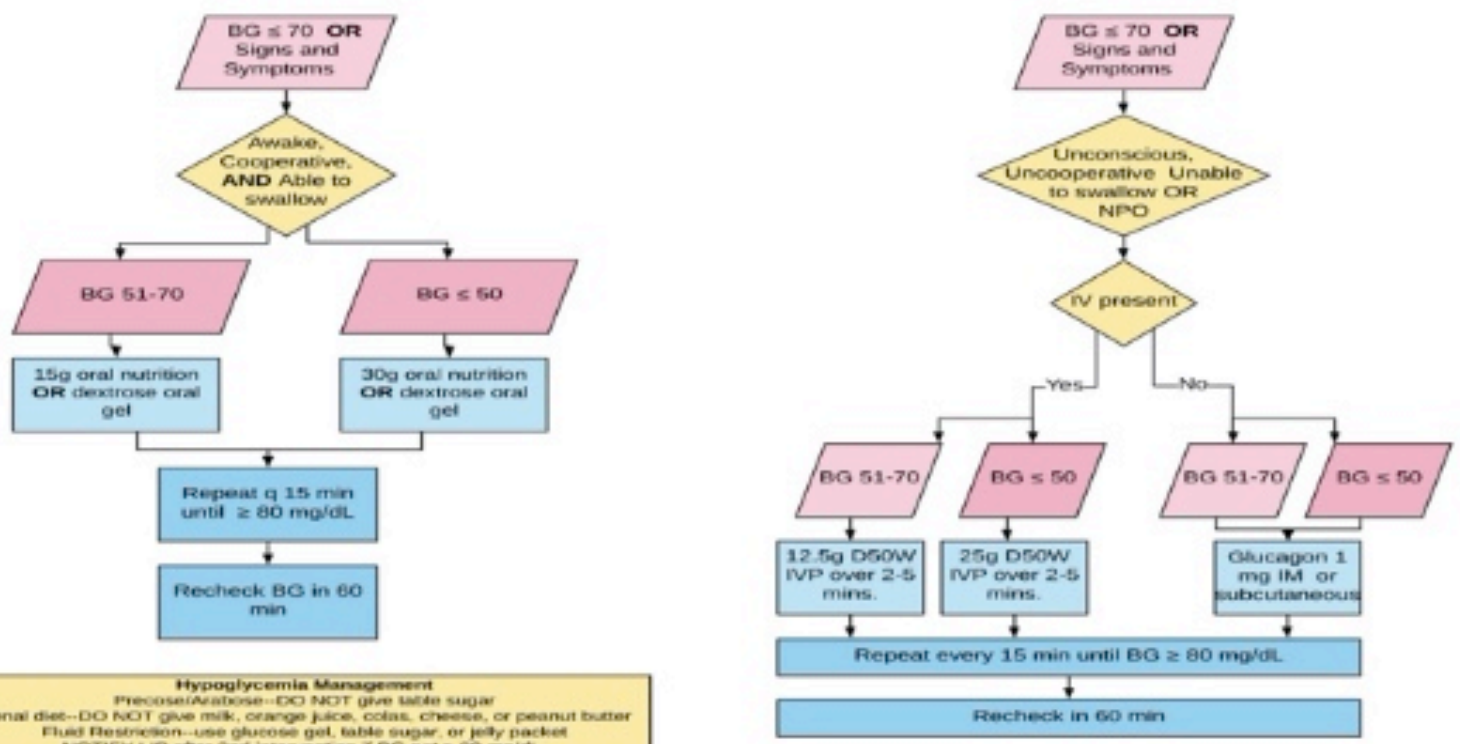


\section{Table 2}

Demographic, Process, Outcome, Balancing, Sustainability Variable Table

\begin{tabular}{|c|c|c|c|c|}
\hline & Variable Name & $\begin{array}{l}\text { Variable } \\
\text { Description }\end{array}$ & $\begin{array}{l}\text { Possible } \\
\text { Range of } \\
\text { Values }\end{array}$ & $\begin{array}{l}\text { Level of } \\
\text { Measurement }\end{array}$ \\
\hline \multirow[t]{4}{*}{$\begin{array}{l}\text { Population } \\
\text { Demographics }\end{array}$} & MRN & $\begin{array}{l}\text { Unique } \\
\text { identifiable } \\
\text { number }\end{array}$ & NA & Text \\
\hline & Age & $\begin{array}{l}\text { Age at time of } \\
\text { HGE }\end{array}$ & $15-110$ & Ratio \\
\hline & Gender & $\begin{array}{l}\text { Biological } \\
\text { gender }\end{array}$ & $\begin{array}{l}1=\text { Male } \\
2=\text { Female }\end{array}$ & Nominal \\
\hline & DM Type & DM diagnosis & $\begin{array}{l}1=\text { Type } 1 \\
2=\text { Type } 2 \\
3=\text { Pre DM } \\
4=\text { None }\end{array}$ & Nominal \\
\hline Process & $\begin{array}{l}\text { Percent protocol } \\
\text { adherence }\end{array}$ & $\begin{array}{l}\text { Completed all } \\
4 \text { steps to the } \\
\text { protocol }\end{array}$ & $\begin{array}{l}1=\text { Yes } \\
2=\text { No }\end{array}$ & Ordinal \\
\hline Outcome & TTN & $\begin{array}{l}\text { Minutes from } \\
\text { HGE to } \\
\text { euglycemia }\end{array}$ & $10-360 \mathrm{~min}$ & Ratio \\
\hline Balancing & $\begin{array}{l}\text { Percent } \\
\text { hyperglycemia } \\
\text { events PPD }\end{array}$ & $\begin{array}{l}\mathrm{BG} \geq 180 \\
\mathrm{mg} / \mathrm{dL}\end{array}$ & $0-100$ & Ratio \\
\hline Sustainability & $\begin{array}{l}\text { Percent } \\
\text { decrease in } \\
\text { TTN from } \\
\text { baseline }\end{array}$ & $\begin{array}{l}\text { Decrease in } \\
\text { minutes from } \\
\text { TTN from } \\
\text { baseline to the } \\
\text { end of the } \\
\text { project }\end{array}$ & $0-100$ & Ratio \\
\hline
\end{tabular}

Note. $\overline{\mathrm{MRN}}=$ Medical Record Number; HGE = hypoglycemia event; DM = diabetes mellitus; $\mathrm{TTN}=$ time to normal 
Appendix A

\section{Summary of Primary Research Evidence}

\begin{tabular}{|c|c|c|c|c|c|c|}
\hline Citation & $\begin{array}{l}\text { Design, Level } \\
\text { Quality Grade }\end{array}$ & $\begin{array}{c}\text { Sample } \\
\text { Sample size }\end{array}$ & $\begin{array}{c}\text { Intervention } \\
\text { Comparison } \\
\text { (Definitions should } \\
\text { include any specific } \\
\text { research tools used along } \\
\text { with reliability \& validity) }\end{array}$ & $\begin{array}{l}\text { Theoretical } \\
\text { Foundation }\end{array}$ & $\begin{array}{l}\text { Outcome } \\
\text { Definition }\end{array}$ & $\begin{array}{c}\text { Usefulness } \\
\text { Results } \\
\text { Key Findings }\end{array}$ \\
\hline $\begin{array}{l}\text { Abusamaan, M., Klonoff, D., \& } \\
\text { Mathioudakis, N. (2019). } \\
\text { Predictors of time-to-repeat of } \\
\text { point- of-care glucose } \\
\text { following hypoglycemic events } \\
\text { in hospitalized patients. Journal } \\
\text { of Diabetes Science and } \\
\text { Technology, 14(3), 526-534. } \\
\text { https://www.doi.org/10.1177/19 } \\
\text { 32296819883332 }\end{array}$ & $\begin{array}{l}\text { Retrospective } \\
\text { cross-sectional } \\
\text { analysis } \\
\text { SORT } 2 \\
\text { GRADE Moderate }\end{array}$ & $\begin{array}{l}993,395 \text { POC } \\
\text { total readings } \\
\text { from } 6226 \\
\text { hospital } \\
\text { admissions } \\
\text { over } 3 \text { years. } \\
5234 \text { unique } \\
\text { adult patients. } \\
\text { Patients } \\
\text { included were } \\
\text { those with at } \\
\text { least } 5 \text { POCG } \\
\text { readings } \\
\text { during } \\
\text { hospitalization }\end{array}$ & $\begin{array}{l}\text { Evaluate clinical factors } \\
\text { that are associated with } \\
\text { TTR in hospitalized } \\
\text { patients with } \\
\text { hypoglycemia. POCG } \leq 15 \\
\text { min compared to POCG } \geq \\
15 \text { min. }\end{array}$ & & $\begin{array}{l}\text { Hypoglycemia } \leq \\
70 \mathrm{mg} / \mathrm{dL} . \text { TTR } \\
\text { defined as the } \\
\text { difference in time } \\
\text { (min) between the } \\
\text { index POCG and } \\
\text { the next POCG }\end{array}$ & $\begin{array}{l}\text { Median TTR } \\
\text { was } 49 \text { min. } \\
\text { Low adherence } \\
\text { to TTR POCG } \\
\text { testing after a } \\
\text { hypoglycemia } \\
\text { event. Only } \\
14 \% \text { compliance } \\
\text { with TTR per } \\
\text { hospital } \\
\text { hypoglycemia } \\
\text { protocol }\end{array}$ \\
\hline $\begin{array}{l}\text { Anthony, M. (2007). Treatment } \\
\text { of hypoglycemia in hospitalized } \\
\text { adults. The Diabetes Educator, } \\
\text { 33(4), 709-715. } \\
\text { https://www.doi.org/10.1177/01 } \\
\text { 45721707303806 }\end{array}$ & 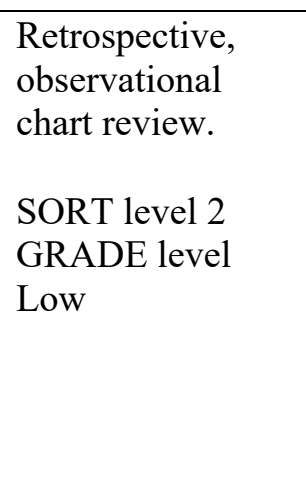 & $\begin{array}{l}\text { Cohort sample } \\
\text { of } 105 \\
\text { medical- } \\
\text { surgical } \\
\text { patients at two } \\
\text { hospitals. }\end{array}$ & $\begin{array}{l}\text { Nursing adherence to a } \\
\text { nurse-driven hypoglycemia } \\
\text { protocol compared to } 100 \% \\
\text { adherence }\end{array}$ & Unknown & $\begin{array}{l}\text { Compliance to a } \\
\text { nurse-driven five- } \\
\text { step bundle: } \\
\text { Administration of } \\
15 \mathrm{~g} \text { of } \\
\text { carbohydrates, FS } \\
\text { retest in } 15 \text { min, } \\
\text { repeat FS } 1 \text { hour } \\
\text { after HGE } \\
\text { resolved, physician } \\
\text { notification, and }\end{array}$ & $\begin{array}{l}\text { Not one single } \\
\text { case of } \\
\text { adherence to the } \\
\text { hypoglycemia } \\
\text { bundle at both } \\
\text { hospitals. }\end{array}$ \\
\hline
\end{tabular}




\begin{tabular}{|c|c|c|c|c|c|c|}
\hline Citation & $\begin{array}{l}\text { Design, Level } \\
\text { Quality Grade }\end{array}$ & $\begin{array}{c}\text { Sample } \\
\text { Sample size }\end{array}$ & $\begin{array}{c}\text { Intervention } \\
\text { Comparison } \\
\text { (Definitions should } \\
\text { include any specific } \\
\text { research tools used along } \\
\text { with reliability \& validity) } \\
\end{array}$ & $\begin{array}{l}\text { Theoretical } \\
\text { Foundation }\end{array}$ & $\begin{array}{l}\text { Outcome } \\
\text { Definition }\end{array}$ & $\begin{array}{c}\text { Usefulness } \\
\text { Results } \\
\text { Key Findings }\end{array}$ \\
\hline & & & & & $\begin{array}{l}\text { HGE } \\
\text { documentation }\end{array}$ & \\
\hline $\begin{array}{l}\text { Araque, K., Kadayakkar, D., } \\
\text { Gigauri, N., Sheehan, D., } \\
\text { Majumdar, S., Buller, G., \& } \\
\text { Flannery, C. (2018). Reducing } \\
\text { severe hypoglycemia in } \\
\text { hospitalized patients with } \\
\text { diabetes: Early outcomes of } \\
\text { standardized reporting and } \\
\text { management. BMJ Open Access, } \\
\text { 7(e000120), 1-7. } \\
\text { https://www.doi.org/10.1136/bm } \\
\text { joq-2017-000120 }\end{array}$ & 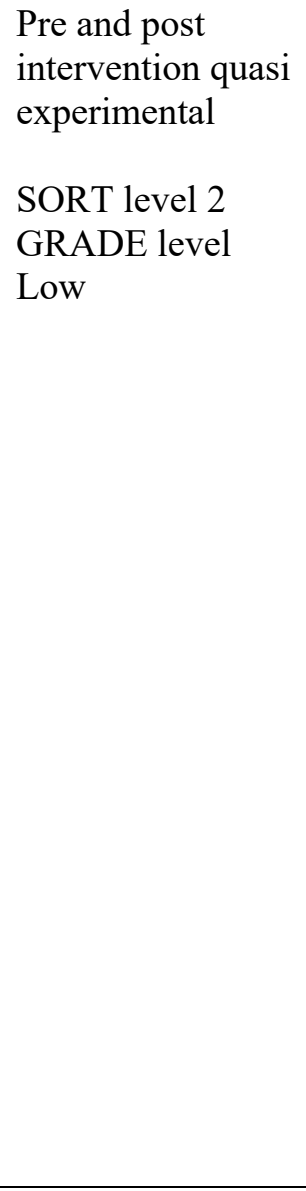 & $\begin{array}{l}\text { Cohort sample } \\
\text { of general } \\
\text { medical } \\
\text { patients. } \\
\text { Sample size: } \\
\text { Pre- } \\
\text { intervention } \\
22 \text { patients, } \\
\text { post- } \\
\text { intervention } \\
27 \text { patients for } \\
\text { a total of } 49 \text {. } \\
\text { All patients } \\
\text { with HGE } \\
\text { with type } 1 \text { or } \\
\text { type } 2 \\
\text { diabetes that } \\
\text { consented to } \\
\text { FS or serum } \\
\text { glucose. } \\
\text { Excluded } \\
\text { patients } \\
\text { without } \\
\text { diabetes and } \\
\text { glucose } \\
\text { performance } \\
\text { errors. }\end{array}$ & $\begin{array}{l}\text { Instituting a nurse-driven } \\
\text { hypoglycemia bundle with } \\
\text { a focus to improve } \\
\text { management of } \\
\text { hypoglycemia: standard } \\
\text { HGE treatment, dextrose } \\
\text { administration per nursing } \\
\text { prior to calling physician } \\
\text { and Pyxis alert to recheck } \\
\text { FS after treatment, insulin } \\
\text { and hypoglycemia order } \\
\text { sets, automatic call to } \\
\text { physician after HGE to } \\
\text { assess risks, automatic } \\
\text { practice alert to consult } \\
\text { endocrinology after two } \\
\text { HGEs, staff badge buddy } \\
\text { with hypoglycemia } \\
\text { protocol, and education of } \\
\text { nursing and medical teams. } \\
\text { Comparison, standard care } \\
\text { pre-bundle. }\end{array}$ & Unknown & $\begin{array}{l}\text { Primary: Time to } \\
\text { recovery, median } \\
\text { time from HGE to } \\
\text { euglycemia and } \\
\text { time to next FS } \\
\text { after HGE } \\
\text { treatment } \\
\text { Secondary: } \\
\text { cumulative } \\
\text { incidence of HGE, } \\
\text { physician } \\
\text { notification rate, } \\
\text { administration of } \\
\text { standard treatment, } \\
\text { and recurrent HGE } \\
\text { in a single } \\
\text { hospitalization. }\end{array}$ & $\begin{array}{l}\text { Median time to } \\
\text { recovery } \\
\text { declined post- } \\
\text { intervention by } \\
138 \text { minutes ( } 61 \\
\%), p=0.03 \text {. } \\
\text { Time to follow } \\
\text { up FS decreased } \\
\mathrm{p}<0.001 \text {. } \\
\text { Cumulative } \\
\text { incidence of } \\
\text { HGE decreased, } \\
\text { physician } \\
\text { notification } \\
\text { increased, } \\
\text { administration } \\
\text { of standard } \\
\text { treatment } \\
\text { increased. } \\
\text { Developing and } \\
\text { supporting the } \\
\text { use of a } \\
\text { standardized } \\
\text { hypoglycemia } \\
\text { protocol is } \\
\text { effective. }\end{array}$ \\
\hline $\begin{array}{l}\text { Coats, A., \& Marshall, D. } \\
\text { (2013). Inpatient } \\
\text { hypoglycaemia: A study of }\end{array}$ & $\begin{array}{l}\text { Non-experimental } \\
\text { observational } \\
\text { research: }\end{array}$ & $\begin{array}{l}\text { Cohort sample } \\
\text { of } 32 \text { medical- } \\
\text { surgical }\end{array}$ & $\begin{array}{l}\text { Nursing adherence to a } \\
\text { nurse-driven hypoglycemia }\end{array}$ & Unknown & $\begin{array}{l}\text { HGE defined as }< \\
4.0 \mathrm{mmol} / 1=72 \\
\mathrm{mg} / \mathrm{dL} . \text { Adherence }\end{array}$ & $\begin{array}{l}\text { Low adherence } \\
\text { to hypoglycemia } \\
\text { protocol }\end{array}$ \\
\hline
\end{tabular}




\begin{tabular}{|c|c|c|c|c|c|c|}
\hline Citation & $\begin{array}{l}\text { Design, Level } \\
\text { Quality Grade }\end{array}$ & $\begin{array}{c}\text { Sample } \\
\text { Sample size }\end{array}$ & $\begin{array}{c}\text { Intervention } \\
\text { Comparison } \\
\text { (Definitions should } \\
\text { include any specific } \\
\text { research tools used along } \\
\text { with reliability \& validity) }\end{array}$ & $\begin{array}{l}\text { Theoretical } \\
\text { Foundation }\end{array}$ & $\begin{array}{l}\text { Outcome } \\
\text { Definition }\end{array}$ & $\begin{array}{c}\text { Usefulness } \\
\text { Results } \\
\text { Key Findings }\end{array}$ \\
\hline $\begin{array}{l}\text { nursing management. Nursing } \\
\text { Praxis in New Zealand, 29(2), } \\
\text { 15-24. http://prx- } \\
\text { usa.lirn.net/login?url=http://sear } \\
\text { ch.ebscohost.com/login.aspx?dir } \\
\text { ect=true\&db=ccm\&AN=107966 } \\
515 \& \text { site=eds-live }\end{array}$ & $\begin{array}{l}\text { Descriptive } \\
\text { retrospective chart } \\
\text { review } \\
\text { SORT level } 2 \\
\text { GRADE level } \\
\text { Low }\end{array}$ & $\begin{array}{l}\text { patients. Type } \\
1 \text { or type } 2 \\
\text { diabetes } \\
\text { patients with } \\
\text { an episode of } \\
\text { hypoglycemia } \\
\text { during a 3- } \\
\text { month period. } \\
\text { Excluded diet } \\
\text { controlled } \\
\text { only patients }\end{array}$ & $\begin{array}{l}\text { protocol compared to } 100 \% \\
\text { adherence }\end{array}$ & & $\begin{array}{l}\text { to all eight steps of } \\
\text { a hypoglycemia } \\
\text { protocol: } 9-15 \mathrm{~g} \\
\text { glucose, retest in } \\
10-15 \text { minutes, } \\
\text { retreat with glucose } \\
\text { only if }<4 \text { mmol/1, } \\
\text { withhold complex } \\
\mathrm{CHO} \text { until } \mathrm{CBG}> \\
4 \mathrm{mmol} / \mathrm{l}, \mathrm{Gives} \\
\mathrm{CHO} \text { snack/meal } \\
\text { when } \mathrm{CBG}>4 \\
\text { mmol/1, gives usual } \\
\text { diabetic medication } \\
\text { at prescribed times } \\
\text { when } \mathrm{CBG}>4 \\
\text { mmol/1, informs } \\
\text { medical staff of } \\
\text { hypoglycemia, } \\
\text { documents } \\
\text { interventions. }\end{array}$ & $\begin{array}{l}\text { resulting in } \\
43.8 \% \\
\text { recurrence of } \\
\text { hypoglycemia. } \\
\text { Non-adherence } \\
\text { to the } \\
\text { hypoglycemia } \\
\text { protocol has } \\
\text { negative patient } \\
\text { outcomes. } \\
\text { Recommend } \\
\text { further } \\
\text { interventional } \\
\text { studies to } \\
\text { improved } \\
\text { adherence }\end{array}$ \\
\hline $\begin{array}{l}\text { Engvall, J., Padula, C., } \\
\text { Krajewski, A., Rourke, J., } \\
\text { McGillivray, C., Desroches, S., } \\
\text { \& Anger, W. (2014). } \\
\text { Empowering the development of } \\
\text { a nurse-driven protocol. } \\
\text { Medsurg Nursing, 23(3), 149- } \\
\text { 154. } \\
\text { http://www.medsurgnursing.net/ } \\
\text { cgi- }\end{array}$ & $\begin{array}{l}\text { Non-experimental: } \\
\text { pre and post } \\
\text { intervention } \\
\text { SORT level } 3 \\
\text { GRADE level } \\
\text { very low }\end{array}$ & $\begin{array}{l}\text { Convenience } \\
\text { sample of } \\
\text { nurses } n=25\end{array}$ & $\begin{array}{l}\text { Development of a nurse- } \\
\text { driven hypoglycemia } \\
\text { protocol with a focus on the } \\
\text { nurse response to use and } \\
\text { effectiveness. }\end{array}$ & Unknown & $\begin{array}{l}\text { Nurse } \\
\text { questionnaire with } \\
8 \text { questions related } \\
\text { to the accessibility } \\
\text { and ease of } \\
\text { protocol use, type } \\
\text { of treatment used, } \\
\text { and sense of nurse } \\
\text { autonomy }\end{array}$ & $\begin{array}{l}\text { Post } \\
\text { intervention } \\
\text { nurse survey: } \\
90 \% \text { found the } \\
\text { protocol easy to } \\
\text { use, } 90 \% \text { found } \\
\text { the protocol } \\
\text { effective in } \\
\text { improving the } \\
\text { outcome of the } \\
\text { HGE. } 86 \%\end{array}$ \\
\hline
\end{tabular}




\begin{tabular}{|c|c|c|c|c|c|c|}
\hline Citation & $\begin{array}{l}\text { Design, Level } \\
\text { Quality Grade }\end{array}$ & $\begin{array}{c}\text { Sample } \\
\text { Sample size }\end{array}$ & $\begin{array}{c}\text { Intervention } \\
\text { Comparison } \\
\text { (Definitions should } \\
\text { include any specific } \\
\text { research tools used along } \\
\text { with reliability \& validity) } \\
\end{array}$ & $\begin{array}{l}\text { Theoretical } \\
\text { Foundation }\end{array}$ & $\begin{array}{l}\text { Outcome } \\
\text { Definition }\end{array}$ & $\begin{array}{l}\text { Usefulness } \\
\text { Results } \\
\text { Key Findings }\end{array}$ \\
\hline $\begin{array}{l}\text { bin/WebObjects/MSNJournal.w } \\
\text { oa }\end{array}$ & & & & & & $\begin{array}{l}\text { reported } \\
\text { increased nurse } \\
\text { autonomy in } \\
\text { managing HGE. } \\
\text { Use of a } \\
\text { hypoglycemia } \\
\text { protocol } \\
\text { increases nurse } \\
\text { autonomy and } \\
\text { patient } \\
\text { outcomes. }\end{array}$ \\
\hline $\begin{array}{l}\text { Gaston, S. (1992). Outcomes of } \\
\text { hypoglycemia treated by } \\
\text { standardized protocol in a } \\
\text { community hospital. The } \\
\text { Diabetes Educator, 18(6), 491- } \\
494 \text {. } \\
\text { https://journals.sagepub.com/ho } \\
\text { me/tde }\end{array}$ & $\begin{array}{l}\text { Non-experimental } \\
\text { observational: } \\
\text { retrospective chart } \\
\text { review } \\
\text { SORT level } 2 \\
\text { GRADE level low }\end{array}$ & $\begin{array}{l}\text { Cohort } \mathrm{n}=92 \\
\text { non-critical } \\
\text { adult patients } \\
\text { from one } \\
\text { hospital }\end{array}$ & $\begin{array}{l}\text { Observe the patient } \\
\text { outcomes when a nurse- } \\
\text { driven hypoglycemia } \\
\text { protocol was followed }\end{array}$ & Unknown & $\begin{array}{l}\text { Date and time of } \\
\text { episode; presence } \\
\text { or absence of } \\
\text { symptoms; } \\
\text { treatment(s); lowest } \\
\text { FS blood glucose } \\
15 \text { minutes and } 1 \\
\text { hour after } \\
\text { treatment; meal } \\
\text { provided in } \\
\text { conjunction with } \\
\text { treatment; time, } \\
\text { type, and dose of } \\
\text { the most recent } \\
\text { hypoglycemia } \\
\text { medication; and } \\
\text { demographic data. }\end{array}$ & $\begin{array}{l}92 \text { patients had } \\
179 \text { episodes of } \\
\text { hypoglycemia } \\
\text { with only } 1 \\
\text { patient having a } \\
\text { change in } \\
\text { therapy after the } \\
\text { HGE. } \\
\text { Undertreatment } \\
\text { and } \\
\text { overtreatment } \\
\text { occurred due to } \\
\text { poor adherence } \\
\text { to the protocol. } \\
\text { Hypoglycemia } \\
\text { protocol } \\
\text { adherence and } \\
\text { patient } \\
\text { outcomes should } \\
\text { be monitored. }\end{array}$ \\
\hline
\end{tabular}




\begin{tabular}{|c|c|c|c|c|c|c|}
\hline Citation & $\begin{array}{l}\text { Design, Level } \\
\text { Quality Grade }\end{array}$ & $\begin{array}{c}\text { Sample } \\
\text { Sample size }\end{array}$ & $\begin{array}{c}\text { Intervention } \\
\text { Comparison } \\
\text { (Definitions should } \\
\text { include any specific } \\
\text { research tools used along } \\
\text { with reliability \& validity) }\end{array}$ & $\begin{array}{l}\text { Theoretical } \\
\text { Foundation }\end{array}$ & $\begin{array}{l}\text { Outcome } \\
\text { Definition }\end{array}$ & $\begin{array}{c}\text { Usefulness } \\
\text { Results } \\
\text { Key Findings }\end{array}$ \\
\hline $\begin{array}{l}\text { Hermayer, K., Cawley, P., } \\
\text { Arnold, P., Sutton, A., Crudup, } \\
\text { J., Kozlowski, L., Hushion, T., } \\
\text { Sheakley, M., Epps, J., Weil, R., } \\
\text { \& Carter, R. (2009). Impact of } \\
\text { improvement efforts on } \\
\text { glycemic control and } \\
\text { hypoglycemia at a university } \\
\text { medical center. Journal of } \\
\text { Hospital Medicine, 4, 331-339. } \\
\text { https://www.doi.org/10.1002/jh } \\
\text { m.449 }\end{array}$ & $\begin{array}{l}\text { Non-experimental } \\
\text { observational: } \\
\text { retrospective chart } \\
\text { review pre and } \\
\text { post intervention } \\
\text { SORT level } 2 \\
\text { GRADE level low }\end{array}$ & $\begin{array}{l}\text { Cohort sample } \\
\text { including all } \\
\text { patients from } \\
\text { one hospital } \\
\text { who had a } \\
\text { documented } \\
\text { history of } \\
\text { diabetes or } \\
\text { who had at } \\
\text { least } 1 \text { FS } \\
\text { blood glucose } \\
\text { above } 180 \\
\text { mg/dL. } 11,715 \\
\text { patient-days, } \\
56,401 \\
\text { individual BG } \\
\text { readings from } \\
2215 \text { unique } \\
\text { patients across } \\
\text { four years. }\end{array}$ & $\begin{array}{l}\text { Development and } \\
\text { institution of a nurse-driven } \\
\text { hypoglycemia, } \\
\text { hyperglycemia, } \\
\text { subcutaneous insulin and } \\
\text { intravenous insulin } \\
\text { treatment protocols. Insulin } \\
\text { order sets including a } \\
\text { nurse-driven hypoglycemia } \\
\text { protocol }\end{array}$ & Unknown & $\begin{array}{l}\text { Number of HGE, } \\
\text { and hyperglycemia } \\
\text { episodes per } 1000 \\
\text { patient days. HGE } \\
\text { defined as }<70 \\
\text { mg/dL. Mild, } \\
\text { moderate, and } \\
\text { severe were defined } \\
\text { as } 50-69 \mathrm{mg} / \mathrm{dL} \text {, } \\
40-49 \mathrm{mg} / \mathrm{dL} \text {, and }< \\
40 \mathrm{mg} / \mathrm{dL} \\
\text { respectively }\end{array}$ & $\begin{array}{l}\text { There were no } \\
\text { statistical } \\
\text { differences in } \\
\text { HGE post } \\
\text { intervention. } \\
\text { Nursing } \\
\text { adherence to } \\
\text { protocol was not } \\
\text { measured. }\end{array}$ \\
\hline $\begin{array}{l}\text { Kadayakkara, D., } \\
\text { Balasubramanian, P., Araque, } \\
\text { K., Davis, K., Javed, F., \& } \\
\text { Niaki, P. (2019). } \\
\text { Multidisciplinary strategies to } \\
\text { treat severe hypoglycemia in } \\
\text { hospitalized patients with } \\
\text { diabetes mellitus reduce } \\
\text { inpatient mortality rate: } \\
\text { Experience from an academic } \\
\text { community hospital. PloS ONE, } \\
\text { 14(8), 1-5. }\end{array}$ & $\begin{array}{l}\text { Retrospective pre- } \\
\text { and post- } \\
\text { intervention study } \\
\text { SORT level } 2 \\
\text { GRADE level } \\
\text { moderate }\end{array}$ & $\begin{array}{l}\text { Cohort sample } \\
\text { of medical- } \\
\text { surgical } \\
\text { patients in } 1 \\
\text { hospital. } \mathrm{n}= \\
2416 \text { pre- } \\
\text { intervention } \\
\text { and } 3607 \\
\text { postinterventi } \\
\text { on. } \\
\text { Excluded: } \\
\text { patients }\end{array}$ & $\begin{array}{l}\text { Formed an interdisciplinary } \\
\text { committee that instituting a } \\
\text { hypoglycemia bundle and } \\
\text { measured that on mortality: } \\
\text { standard HGE treatment, } \\
\text { dextrose administration per } \\
\text { nursing prior to calling } \\
\text { physician and Pyxis alert to } \\
\text { recheck FS after treatment, } \\
\text { insulin and hypoglycemia } \\
\text { order sets, automatic call to } \\
\text { physician after HGE to }\end{array}$ & Unknown & $\begin{array}{l}\text { Incidence of severe } \\
\text { hypoglycemia, in- } \\
\text { patient mortality, } \\
\text { 30-day mortality } \\
\text { and } 30 \text {-day } \\
\text { readmission rates. } \\
\text { Time to recovery, } \\
\text { median time from } \\
\text { HGE to euglycemia } \\
\text { (BG } \geq 80 \mathrm{mg} / \mathrm{dL} \text { ) } \\
\text { and time to next FS } \\
\text { after HGE }\end{array}$ & $\begin{array}{l}\text { There were } \\
\text { improved or } \\
\text { unchanged } \\
\text { results post- } \\
\text { intervention. } \\
\text { Some not } \\
\text { statistically but } \\
\text { clinically } \\
\text { significant. The } \\
\text { hypoglycemia } \\
\text { bundle of care } \\
\text { reduced }\end{array}$ \\
\hline
\end{tabular}




\begin{tabular}{|c|c|c|c|c|c|c|}
\hline Citation & $\begin{array}{l}\text { Design, Level } \\
\text { Quality Grade }\end{array}$ & $\begin{array}{c}\text { Sample } \\
\text { Sample size }\end{array}$ & $\begin{array}{c}\text { Intervention } \\
\text { Comparison } \\
\text { (Definitions should } \\
\text { include any specific } \\
\text { research tools used along } \\
\text { with reliability \& validity) }\end{array}$ & $\begin{array}{l}\text { Theoretical } \\
\text { Foundation }\end{array}$ & $\begin{array}{l}\text { Outcome } \\
\text { Definition }\end{array}$ & $\begin{array}{c}\text { Usefulness } \\
\text { Results } \\
\text { Key Findings }\end{array}$ \\
\hline $\begin{array}{l}\text { https://www.doi.org/10.1371/joi } \\
\text { urnal.pone.0220956 }\end{array}$ & & $\begin{array}{l}\text { admitted or } \\
\text { transferred to } \\
\text { ICU, } \\
\text { psychiatric } \\
\text { wards and } \\
\text { OB/GYN } \\
\text { wards }\end{array}$ & $\begin{array}{l}\text { assess risks, automatic } \\
\text { practice alert to consult } \\
\text { endocrinology after two } \\
\text { HGEs, staff badge buddy } \\
\text { with hypoglycemia } \\
\text { protocol, and education of } \\
\text { nursing and medical teams. } \\
\text { Comparison, standard care } \\
\text { pre bundle. }\end{array}$ & & $\begin{array}{l}\text { treatment, } \\
\text { cumulative } \\
\text { incidence of } \mathrm{HGE}, \\
\text { physician } \\
\text { notification rate, } \\
\text { administration of } \\
\text { standard treatment, } \\
\text { and change in } \\
\text { treatment regimen. }\end{array}$ & $\begin{array}{l}\text { inpatient and } \\
\text { 30-day } \\
\text { mortality. }\end{array}$ \\
\hline $\begin{array}{l}\text { Maynard, G., Huynh, M., \& } \\
\text { Renall, M. (2008). Iatrogenic } \\
\text { inpatient hypoglycemia: Risk } \\
\text { factors, treatment, and } \\
\text { prevention: Analysis of current } \\
\text { practice at an academic medical } \\
\text { center with implications for } \\
\text { improvement efforts. Diabetes } \\
\text { Spectrum, 21(4), 241-247. } \\
\text { https://spectrum.diabetesjournals } \\
\text {.org/content/21/4/241 }\end{array}$ & 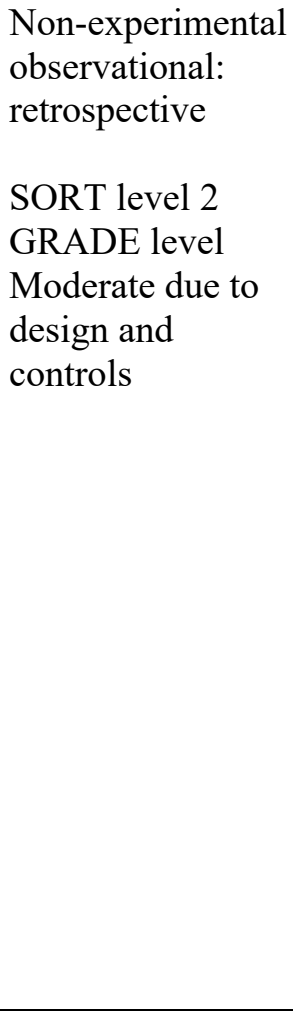 & $\begin{array}{l}\text { Matched case- } \\
\text { control. } 130 \\
\text { adults } \geq 18 \\
\text { years of age; } \\
\text { non-critical } \\
\text { care; with an } \\
\text { HGE were } \\
\text { compared to } \\
\text { patients that } \\
\text { did not have a } \\
\text { HGE on the } \\
\text { same day via a } \\
\text { computer- } \\
\text { generated } \\
\text { daily report. }\end{array}$ & $\begin{array}{l}\text { Examine the patient and } \\
\text { hospital care risk factors for } \\
\text { experiencing a } \\
\text { hypoglycemic patient-day, } \\
\text { compared to similar control } \\
\text { patients who were not } \\
\text { experiencing a } \\
\text { hypoglycemic patient-day }\end{array}$ & Unknown & $\begin{array}{l}\text { HGE defined as } \leq \\
60 \mathrm{mg} / \mathrm{dL} \text {. } \\
\text { Demographics and } \\
\text { medication history, } \\
\text { comorbidities, } \\
\text { nutritional status. } \\
\text { Euglycemia } \\
\text { defined as } \geq 80 \\
\mathrm{mg} / \mathrm{dL}\end{array}$ & $\begin{array}{l}\text { Median time } \\
\text { until the next } \\
\text { glucose value } \\
\text { was checked } \\
\text { was } 60 \text { min as } \\
\text { opposed to } 15 \\
\text { min per } \\
\text { protocol, the } \\
\text { median time } \\
\text { until euglycemia } \\
\text { was } 180 \text { min } \\
\text { with a range of } \\
10-1260 \text { min. } \\
29.2 \% \text { of HGEs } \\
\text { were not } \\
\text { documented } \\
\text { anywhere in the } \\
\text { chart. } \\
\text { Documentation } \\
\text { and adherence } \\
\text { to protocol was } \\
\text { suboptimal. } \\
\text { Monitoring }\end{array}$ \\
\hline
\end{tabular}




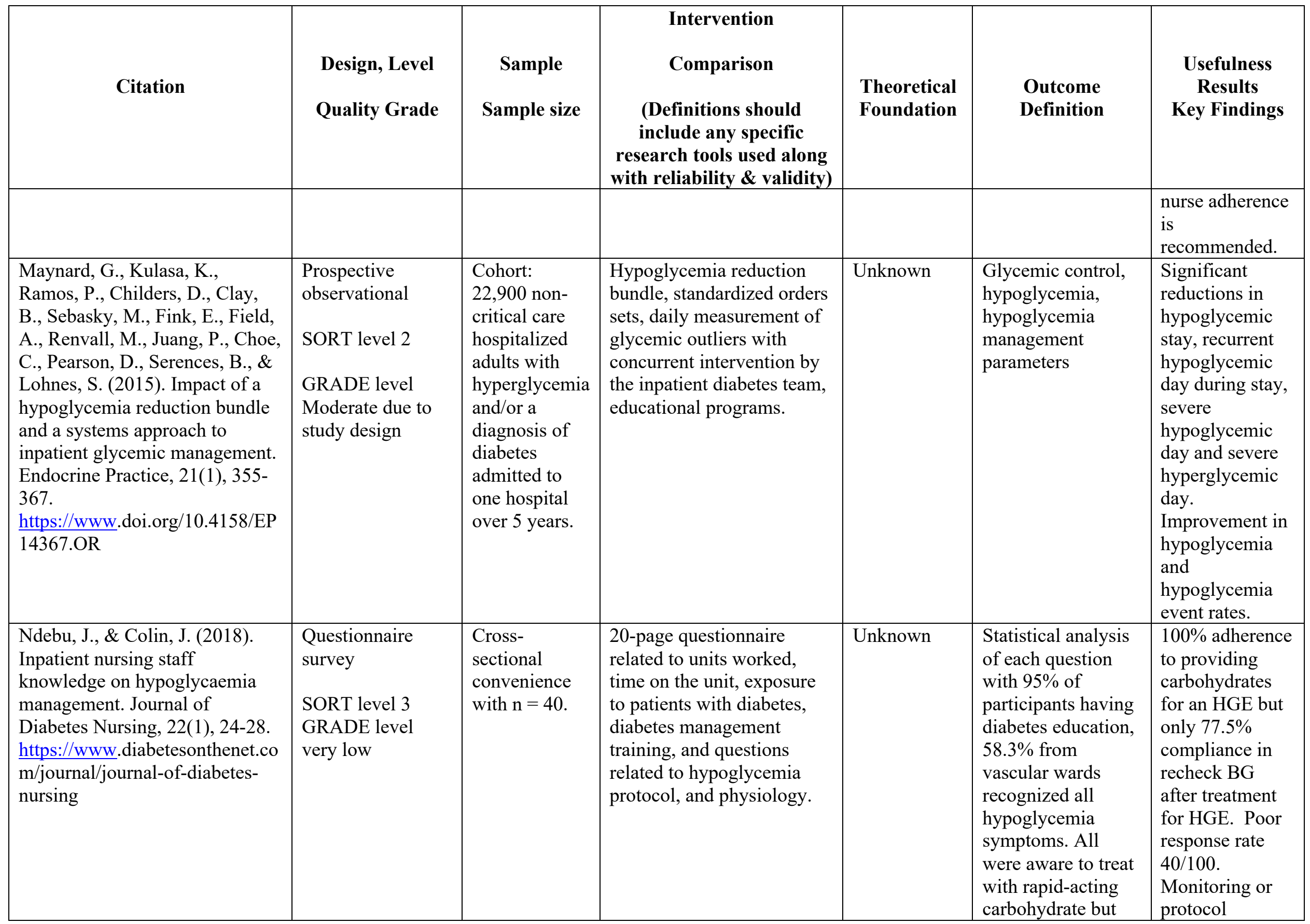




\begin{tabular}{|c|c|c|c|c|c|c|}
\hline Citation & $\begin{array}{l}\text { Design, Level } \\
\text { Quality Grade }\end{array}$ & $\begin{array}{c}\text { Sample } \\
\text { Sample size }\end{array}$ & $\begin{array}{c}\text { Intervention } \\
\text { Comparison } \\
\text { (Definitions should } \\
\text { include any specific } \\
\text { research tools used along } \\
\text { with reliability \& validity) }\end{array}$ & $\begin{array}{l}\text { Theoretical } \\
\text { Foundation }\end{array}$ & $\begin{array}{l}\text { Outcome } \\
\text { Definition }\end{array}$ & $\begin{array}{l}\text { Usefulness } \\
\text { Results } \\
\text { Key Findings }\end{array}$ \\
\hline & & & & & $\begin{array}{l}\text { only } 77.5 \% \\
\text { rechecked the BG } \\
\text { after } 15 \text { minutes as } \\
\text { per protocol. }\end{array}$ & $\begin{array}{l}\text { adherence and } \\
\text { pathophysiology } \\
\text { of hypoglycemia } \\
\text { may be valuable } \\
\text { to patient } \\
\text { outcomes. }\end{array}$ \\
\hline $\begin{array}{l}\text { Pandey, S., Chauhan, A. (2015). } \\
\text { Achieving } 100 \% \text { reporting of } \\
\text { hypoglycemia in a tertiary care } \\
\text { hospital through a structured } \\
\text { action pathway \& persistent } \\
\text { monitoring tool among nurses. } \\
\text { International Journal of Nursing } \\
\text { Education, } 7(2), 111-115 . \\
\text { https://www.doi.org/10.5958/09 } \\
74-9357.2015 .00085 .9\end{array}$ & $\begin{array}{l}\text { Prospective, } \\
\text { observational: pre } \\
\text { and post over } 3 \\
\text { years } \\
\text { SORT level } 2 \\
\text { GRADE level low }\end{array}$ & Cohort & $\begin{array}{l}\text { Implementing a nurse- } \\
\text { driven hypoglycemia } \\
\text { protocol based on ADA } \\
\text { guidelines. Each HGE was } \\
\text { reviewed within } 24 \text { hours to } \\
\text { review the performance of } \\
\text { the first responder. Nursing } \\
\text { education related to the } \\
\text { protocol was conducted. }\end{array}$ & Unknown & $\begin{array}{l}\text { Hypoglycemia }= \\
\text { BG level }<70 \\
\text { mg/dL. Total } \\
\text { number of patients } \\
\text { receiving insulin, } \\
\text { total number of } \\
\text { HGE recorded in } \\
\text { the patient record, } \\
\text { RCA of each } \\
\text { episode }\end{array}$ & $\begin{array}{l}\text { Incidence per } \\
1000 \text { patient } \\
\text { hours of } \\
\text { hypoglycemia } \\
\text { recorded } \\
\text { decreased each } \\
\text { year. Constant } \\
\text { training, } \\
\text { surveillance and } \\
\text { feedback } \\
\text { analysis } \\
\text { decreased } \\
\text { incidence of } \\
\text { hypoglycemia. } \\
\text { RCA indicated a } \\
\text { change in diet } \\
\text { without change } \\
\text { in insulin the } \\
\text { most common } \\
\text { cause of } \\
\text { hypoglycemia. } \\
\text { Nurse-driven } \\
\text { protocols } \\
\text { improve patient } \\
\text { outcomes. }\end{array}$ \\
\hline
\end{tabular}


Legend: $\mathrm{TTR}=$ time to repeat, $\mathrm{POCG}=$ point-of-care glucose, $\mathrm{HGE}=$ hypoglycemic event, $\mathrm{FS}=$ finger stick, $\mathrm{BG}=$ blood glucose, $\mathrm{g}=\mathrm{gram}, \mathrm{min}=$ minute $(\mathrm{s}), \mathrm{CHO}=$ carbohydrate, $\mathrm{CBG}=$ capillary blood glucose, $\mathrm{RCA}=$ root cause analysis 


\section{Appendix B}

\section{SWOT Analysis}

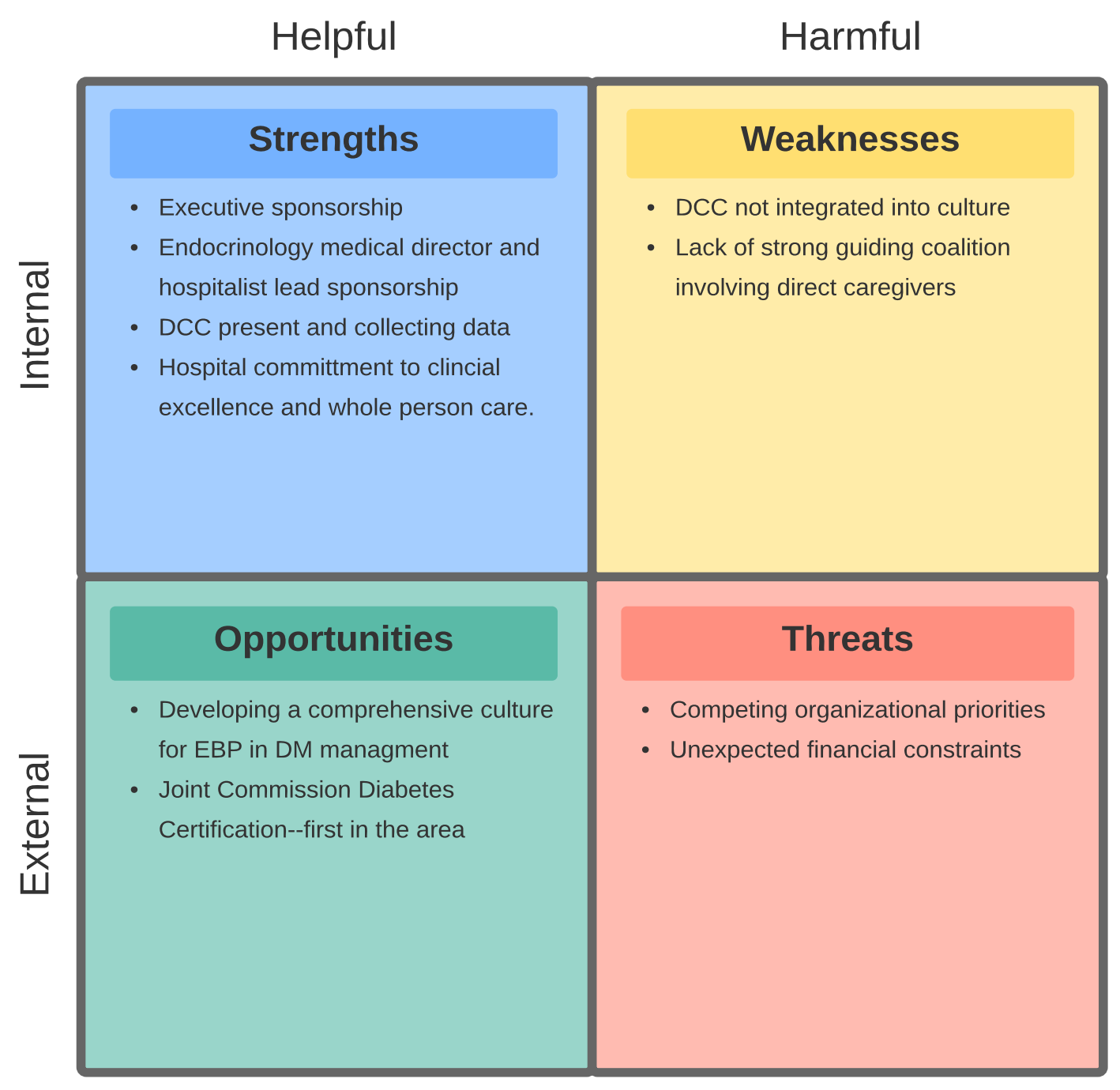




\section{Appendix C}

\section{Project Timeline}

\begin{tabular}{|c|c|c|c|c|c|c|c|c|c|c|c|c|c|c|c|c|c|c|c|c|c|c|c|c|}
\hline & & 801 & & & & & & & & 780 & & & & & & & & 7803 & & & & & & \\
\hline 总 & $\frac{\bar{y}}{3}$ & $\begin{array}{l}m \\
\frac{n}{0} \\
3 \\
3\end{array}$ & $\frac{n}{3}$ & $\frac{5}{8}$ & $\frac{a}{y}$ & $\begin{array}{l}z \\
y \\
\frac{y}{3} \\
3\end{array}$ & $\begin{array}{l}\frac{m}{4} \\
\frac{y}{8} \\
3\end{array}$ & $\begin{array}{l}n \\
\frac{n}{0} \\
3 \\
3\end{array}$ & $\frac{\bar{y}}{3}$ & $\begin{array}{l}m \\
\frac{n}{2} \\
3 \\
3\end{array}$ & $\begin{array}{l}n \\
\frac{y}{ \pm} \\
\dot{8}\end{array}$ & $\frac{y}{8}$ & $\begin{array}{l}9 \\
\frac{4}{0} \\
3\end{array}$ & $\begin{array}{l}= \\
y \\
\frac{y}{0} \\
3\end{array}$ & $\frac{m}{\frac{m}{0}}$ & $\begin{array}{l}n \\
\frac{n}{2} \\
\frac{d}{3}\end{array}$ & $\frac{7}{y}$ & $\begin{array}{l}m \\
\frac{n}{8} \\
\frac{d}{3}\end{array}$ & $\frac{n}{4}$ & $\frac{\bar{y}}{3}$ & $\frac{9}{8}$ & $\begin{array}{l}= \\
y \\
\bar{y} \\
3\end{array}$ & $\begin{array}{l}\frac{m}{4} \\
\frac{y}{2} \\
3\end{array}$ & $\begin{array}{l}n \\
\frac{n}{8} \\
\frac{d}{3}\end{array}$ \\
\hline $\begin{array}{l}\text { Meet with preceptor } \\
\text { and review project } \\
\text { plan }\end{array}$ & & & & & & & & & & & & & & & & & & & & & & & & \\
\hline Meet with IDT & & & & & & & & & & & & & & & & & & & & & & & & \\
\hline $\begin{array}{l}\text { Identify additional } \\
\text { stakeholders and } \\
\text { hypoglycemia nurse } \\
\text { and nurse aide } \\
\text { champions }\end{array}$ & & & & & & & & & & & & & & & & & & & & & & & & \\
\hline $\begin{array}{l}\text { Meet with IDT and } \\
\text { share literature review }\end{array}$ & & & & & & & & & & & & & & & & & & & & & & & & \\
\hline $\begin{array}{l}\text { Identify risks and } \\
\text { develop risk strategy }\end{array}$ & & & & & & & & & & & & & & & & & & & & & & & & \\
\hline Solidify measures & & & & & & & & & & & & & & & & & & & & & & & & \\
\hline $\begin{array}{l}\text { Review and revise } \\
\text { order sets and policies } \\
\text { as needed }\end{array}$ & & & & & & & & & & & & & & & & & & & & & & & & \\
\hline $\begin{array}{l}\text { Develop project } \\
\text { schedule including } \\
\text { milestones }\end{array}$ & & & & & & & & & & & & & & & & & & & & & & & & \\
\hline $\begin{array}{l}\text { Meet with IDT to } \\
\text { review project } \\
\text { schedule, impact to } \\
\text { workflow }\end{array}$ & & & & & & & & & & & & & & & & & & & & & & & & \\
\hline $\begin{array}{l}\text { Review and propose } \\
\text { budget requirements }\end{array}$ & & & & & & & & & & & & & & & & & & & & & & & & \\
\hline $\begin{array}{l}\text { Develop } \\
\text { dissemination/commu } \\
\text { nication plan }\end{array}$ & & & & & & & & & & & & & & & & & & & & & & & & \\
\hline
\end{tabular}




\begin{tabular}{|c|c|c|c|c|c|c|c|c|c|c|c|c|c|c|c|c|c|c|c|c|c|c|c|c|}
\hline & $\mathrm{NU}$ & 801 & & & & & & & & $\mathrm{R} 780$ & & & & & & & & 7803 & & & & & & \\
\hline : & $\frac{\bar{y}}{3}$ & $\begin{array}{l}m \\
y \\
y \\
z\end{array}$ & $\begin{array}{l}n \\
\frac{4}{0} \\
3\end{array}$ & $\frac{5}{2}$ & $\begin{array}{l}9 \\
\frac{1}{2} \\
3\end{array}$ & $\begin{array}{l}= \\
y \\
\frac{1}{d} \\
3\end{array}$ & $\begin{array}{l}\frac{m}{y} \\
\frac{y}{0} \\
\frac{d}{3}\end{array}$ & $\begin{array}{l}n \\
\frac{n}{3} \\
3 \\
3\end{array}$ & $\begin{array}{l}\bar{y} \\
\frac{y}{0} \\
3\end{array}$ & $\begin{array}{l}n \\
\frac{1}{2} \\
\frac{2}{3}\end{array}$ & $\begin{array}{l}n \\
\frac{y}{0} \\
3 \\
3\end{array}$ & $\frac{y}{y}$ & $\begin{array}{l}a \\
y \\
\tilde{y} \\
3\end{array}$ & $\begin{array}{l}= \\
\frac{y}{8} \\
\sum_{3}^{2}\end{array}$ & $\begin{array}{l}m \\
\frac{m}{0} \\
3\end{array}$ & $\begin{array}{l}n \\
\frac{1}{8} \\
3 \\
3\end{array}$ & $\begin{array}{l}\bar{y} \\
\frac{y}{0} \\
3\end{array}$ & $\begin{array}{l}m \\
\frac{n}{0} \\
3 \\
3\end{array}$ & $\begin{array}{l}n \\
y \\
\frac{d}{3} \\
3\end{array}$ & $\frac{\pi}{3}$ & $\frac{a}{y}$ & $\begin{array}{l}= \\
\frac{y}{0} \\
3\end{array}$ & $\begin{array}{l}\frac{m}{4} \\
\frac{y}{2} \\
3\end{array}$ & $\begin{array}{l}\frac{n}{4} \\
\frac{4}{3} \\
3\end{array}$ \\
\hline $\begin{array}{l}\text { Meet with IT to } \\
\text { review EHR impact }\end{array}$ & & & & & & & & & & & & & & & & & & & & & & & & \\
\hline $\begin{array}{l}\text { Meet with IDT and } \\
\text { change team to revie } \\
\text { final proposal }\end{array}$ & & & & & & & & & & & & & & & & & & & & & & & & \\
\hline $\begin{array}{l}\text { Meet with quality } \\
\text { director to review } \\
\text { project proposal }\end{array}$ & & & & & & & & & & & & & & & & & & & & & & & & \\
\hline $\begin{array}{l}\text { Confirm support fron } \\
\text { executive team/key } \\
\text { stakeholders }\end{array}$ & & & & & & & & & & & & & & & & & & & & & & & & \\
\hline $\begin{array}{l}\text { Finalize project } \\
\text { proposal }\end{array}$ & & & & & & & & & & & & & & & & & & & & & & & & \\
\hline $\begin{array}{l}\text { Seek University boar } \\
\text { (EPRC) and facility } \\
\text { IRB approval }\end{array}$ & & & & & & & & & & & & & & & & & & & & & & & & \\
\hline $\begin{array}{l}\text { Meet with IDT to } \\
\text { discuss any requeste } \\
\text { revisions }\end{array}$ & & & & & & & & & & & & & & & & & & & & & & & & \\
\hline $\begin{array}{l}\text { Collect baseline data } \\
\text { and hold kickoff } \\
\text { meeting with IDT an } \\
\text { change team }\end{array}$ & & & & & & & & & & & & & & & & & & & & & & & & \\
\hline $\begin{array}{l}\text { Present hypoglycemi } \\
\text { education for nursing } \\
\text { staff on med-surg un } \\
\text { through LMS }\end{array}$ & & & & & & & & & & & & & & & & & & & & & & & & \\
\hline $\begin{array}{l}\text { Begin and continue } \\
\text { collecting data for } \\
\text { HGE to } \\
\text { euglycemia/DCC } \\
\text { rounds daily }\end{array}$ & & & & & & & & & & & & & & & & & & & & & & & & \\
\hline $\begin{array}{l}\text { End date for data } \\
\text { collection }\end{array}$ & & & & & & & & & & & & & & & & & & & & & & & & \\
\hline $\begin{array}{l}\text { Complete statistical } \\
\text { comparisons }\end{array}$ & & & & & & & & & & & & & & & & & & & & & & & & \\
\hline
\end{tabular}




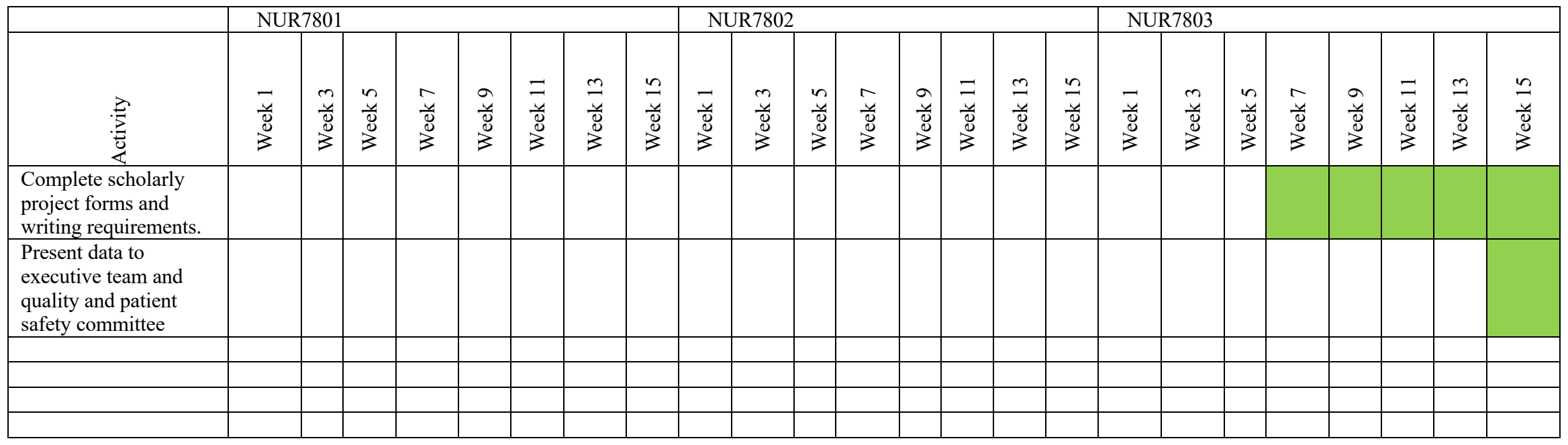




\section{Appendix D}

Hypoglycemia Demographics Data Collection Table

Demographics

\begin{tabular}{|c|c|c|c|c|c|c|}
\hline \multirow[b]{2}{*}{ Age } & \multicolumn{2}{|c|}{ Biological Gender } & \multicolumn{4}{|c|}{ Diagnosis } \\
\hline & Female & Other & Type 1 & Type 2 & Pre & None \\
\hline
\end{tabular}


Clinical Outcome

Date 
Process Outcome/Adherence to Protocol

\begin{tabular}{|c|c|c|c|c|c|c|c|c|}
\hline \multirow[b]{4}{*}{ Date } & \multirow[b]{4}{*}{$\mathrm{q} 15 \mathrm{~min}$} & \multirow[b]{4}{*}{ Doc } & \multirow[b]{4}{*}{ LIP } & \multirow[b]{4}{*}{ Doc } & \multicolumn{3}{|c|}{ Treatment } & \\
\hline & & & & & CCATS & \multicolumn{2}{|l|}{ UUNATS/NPO } & \\
\hline & & & & & \multirow[b]{2}{*}{$51-70 \mathrm{mg} / \mathrm{dL}$} & IV present & No IV & \multirow[b]{2}{*}{ Doc Complete } \\
\hline & & & & & & $51-70 \mathrm{mg} / \mathrm{dL}$ & $\leq 70 \mathrm{mg} / \mathrm{dL}$ & \\
\hline
\end{tabular}

Note. $\mathrm{MRN}=$ Medical record number; Pre = prediabetes; TTN = time to normal recorded in minutes; Doc $=$ documented; $\mathrm{CCATS}=$ Conscious, Cooperative, Able to Swallow; UUNATS/NPO = Uncooperative, Unconscious, Unable to Swallow/nothing by mouth; IV

$=$ Intravenous catheter; q15 $\min =$ every 15 minutes; LIP = licensed independent practitioner 


\section{Appendix E}

\section{Slide Show Outline of Learning Management System Education for Nurses}

- Objectives

- Define hypoglycemia

- Recognize s/sx of hypoglycemia

- Describe the impact of hypoglycemia on the body

- Risks for hypoglycemic events

- Become an expert of the Hypoglycemic Protocol

- How to document properly

- Hypoglycemia Leads to Mortality

- Hypoglycemic events increase mortality by $85.3 \%$

- Increase risk of death by $65.8 \%$ up to one-year post discharge

- 1 occurrence of hypoglycemia increases the chance for more severe occurrences

- Hypoglycemia Definition

- $\quad$ Level 1: $\leq 70 \mathrm{mg} / \mathrm{dL}$

- $\quad$ Level 2: $\leq 50 \mathrm{mg} / \mathrm{dL}$ 
- Level 3: characterized by altered mental and/or physical status requiring assistance from another person for recovery

- Impact of hypoglycemia on the Body

- Cardiac dysrhythmias

- Stroke

- Sympathoadrenal response: this is the "fight or flight" response.

- Causes increased heart rate, cardiac output, blood pressure, and glucose levels

- Repeated sympathoadrenal responses can cause Hypoglycemia Unawareness or Hypoglycemia Associated Autonomic Failure (HAAF). AKA "silent hypoglycemia:

- Your body fails to recognize s/sx of hypoglycemia

- Impact of Hypoglycemia on the body

- Endothelial dysfunction: this is where the inner lining of the small arteries starts failing to perform normal functions.

- Normal function includes:

- Protecting us from toxins

- Regulating the blood-clotting mechanisms

- Controlling our fluid and electrolyte balances

- Impact of Hypoglycemia on the Body 
- Impact of Hypoglycemia on the Body

- Pro-inflammatory state promotes inflammation within the body

- Causing:

- Edema

- Erythema

- Vesicle formation (ulcers, cysts)

- Impact of Hypoglycemia on the Body

- Neuroglycopenia-shortage of glucose (sugar) in the brain

- Leads to:

- $\mathrm{AMS}$

- Vision disturbance

- Falls

- Aspiration

- Anxiety/moodiness/irritability

- Personality changes

- Fatigue/weakness/lethargy 
- Nursing Specific Factors that Increase Risk of Hypoglycemia

- Lack of coordination between dietary and nursing (MEAL TRAY DELIVERY)

- Inadequate glucose monitoring: not checking BG at appropriate times

- Administering Insulin too soon before or after meal/snack

- Failure to report a low blood sugar

- Not treating a low blood sugar because "Asymptomatic"

- Unclear medication orders

- Failure to notify LIP after event or change in patient condition

- Signs and Symptoms of Hypoglycemia

- Hunger

- Nausea

- $\quad$ Fine tremors

- Pallor

- Clamminess

- Palpitations

- Rapid heartbeat
- Weakness

- Numbness/tingling

- Headache

- Anxiety

- Difficulty speaking

- Difficulty thinking "muddled thoughts"

- Stupor 
- Dizziness

- Moodiness

- Blurred vision

- Diplopia

- THE NURSE DRIVEN HYPOGLYCEMIA PROTOCOL

- Initiated by the nurse:

- Can be initiated on anyone, not just diabetes patients

- Whenever a patient's $\mathrm{BG} \leq 70 \mathrm{mg} / \mathrm{dL}$

- You do not have to wait for lab to confirm value

- If patient is unconscious

- Initiate treatment then page rapid response

- The patient shows s/sx of hypoglycemia

It is the RN's responsibility for reassessing, providing treatment, and documenting

- Oral Treatment Concerns

- $\quad$ Patient on dietary renal restriction-Give oral glucose gel (Glutose) AVOID orange juice, colas, milk, peanut butter, cheese

- $\quad$ Patient on fluid restriction: Give oral glucose gel (Glutose), table sugar, or jelly (1packet = 10carbs)
- Unresponsiveness

- Seizures
- $\quad$ Fainting 
- Patient on swallow precautions or puree diet: add 2 tablespoons thickener for every 4oz juice, soda, or milk for treatment

- Patient on Precose (acarbose)- DO NOT treat with table sugar, this will be ineffective

- Hypoglycemia Management

- Once $\mathrm{BG} \geq 80 \mathrm{mg} / \mathrm{dL}$. Recheck 60 minutes

- Notify LIP after 2 interventions

- Notify LIP of an episode if patient is receiving insulin, NPO, TPN, tube feed, poor appetite

- Follow-up treatment

- If meal is $>1$ hour away give snack

- $\quad \mathrm{SNACK}=\mathrm{Carb}+$ Protein

- Graham crackers or Saltines

- Peanut butter or cheese

- $\quad 1 / 2$ sandwich

- $\quad 8$ oz milk

- Nothing sugar free!!!

- Documentation

- If not documented, then patient safety was not maintained 
- Document under Hypoglycemia flow sheet

- Document assessment, unconscious/conscious, symptoms, BG value, treatment given, LIP notification, if rapid or code called, and reassessment after event

- Suggestion: Make a comment or nursing note of event (do not wait until end of shift)

- Documentation in EPIC:

from home screen

- Go to Flowsheet

- $\quad$ Next GO TO Screenings

- Next Select Hypoglycemia from Left panel. It then populates a flowsheet section

- Click in box to document or make a comment. Include BG value, LIP notified, and treatment: 4oz juice, crackers and peanut butter, medications etc...

- $\quad$ Take away points

- One hypoglycemic event can cause lasting harm

- The Hypoglycemia Policy is nurse driven and can be initiated on all patients

- Protocol initiated on any BG $\leq 70 \mathrm{mg} / \mathrm{dL}$, EVEN IF ASYMPTOMATIC

- 15-30 minutes recheck and treat 
- Notify LIP

- Immediately after 2 treatments with a $\mathrm{BG}<80 \mathrm{mg} / \mathrm{dL}$

- On insulin, TF, TPN, NPO, or poor appetite and have an episode

- Any changes in patient condition

- It is the RN's responsibility to treat, reassess, and document 


\section{Appendix F}

\section{Hypoglycemia Pre and Posttest}

1. At which value is a patient thought to be hypoglycemic?
A. $100 \mathrm{mg} / \mathrm{dL}$
B. $90 \mathrm{mg} / \mathrm{dL}$
C. $80 \mathrm{mg} / \mathrm{dL}$
D. $70 \mathrm{mg} / \mathrm{dL}$

2. Prolonged or reoccurring episodes of hypoglycemia can? (select all that apply)
A. Increase risk of cardiovascular disease
B. Increase risk of death
C. Cause permanent damage to organs
D. Cause a spontaneous pneumothorax
E. Cause hypoglycemia unawareness

3. Which of the following are signs and symptoms of hypoglycemia? (select all that apply)
A. Hunger, nausea
B. Clamminess, palpitations, tremors, pallor, weakness
C. Moodiness, anxiety, dizziness, stupor
D. Fainting, unresponsiveness, seizures

4. After how many interventions, for the hypoglycemic patient, whose BG remains $<80$ $\mathrm{mg} / \mathrm{dL}$, should you notify the LIP?
A. 1
B. 2
C. 3 
D. 4

5. Which of these clinical situations can contribute to an increased risk for hypoglycemia? (select all that apply)
A. Change in caloric or carbohydrate intake
B. Change in clinical status or medications
C. Normal saline infusions
D. Failure to adjust glycemic therapies
E. Poor coordination of glucose testing and meal delivery

6. Your patient is conscious, cooperative, and able to swallow. They have an intravenous catheter (IV) in place. Their recent POC value is $55 \mathrm{mg} / \mathrm{dL}$. Which intervention would you choose to treat with first?
A. Give $15 \mathrm{~g}$ oral carbs
B. Give $30 \mathrm{~g}$ oral carbs
C. Administer $12.5 \mathrm{~g}$ Dextrose IV push (IVP)
D. Administer 25g Dextrose IVP

7. Your patient is conscious, uncooperative, and able to swallow. They have an IV in place. Their recent point of care (POC) value is $52 \mathrm{mg} / \mathrm{dL}$. Which intervention would you choose to treat with first?
A. Give $15 \mathrm{~g}$ oral carbs
B. Give $30 \mathrm{~g}$ oral carbs
C. Administer $12.5 \mathrm{~g}$ Dextrose IVP
D. Administer 25g Dextrose IVP 
8. Your patient was given 4 ounces of orange juice for a blood sugar of $66 \mathrm{mg} / \mathrm{dL}$. When is it appropriate to recheck their blood sugar?
A. In 5 minutes
B. In 10 minutes
C. In 15 minutes
D. In 60 minutes

9. Your patient's BG is $42 \mathrm{mg} / \mathrm{dL}$ and they are asymptomatic. They are conscious, cooperative, and able to swallow. Their IV just infiltrated with $0.9 \%$ NS infusion. Which intervention should be done next?
A. Give $30 \mathrm{~g}$ oral carbohydrates
B. Start a new IV
C. Nothing. They are asymptomatic
D. Give 1mg Glucagon IM

10. Your patient has an order for nothing by mouth (NPO) for a stress test in the morning. They are conscious, cooperative, and able to swallow. They received $25 \mathrm{~g}$ Dextrose IVP 16 minutes ago for a BG of $32 \mathrm{mg} / \mathrm{dL}$. You recheck their BG and it is now 48mg/dL. What should you do next?
A. Repeat the intervention and page LIP
B. Call a code blue
C. Notify the LIP and wait for further orders
D. Call the house supervisor 
Appendix G

\section{Project Evaluation Plan}

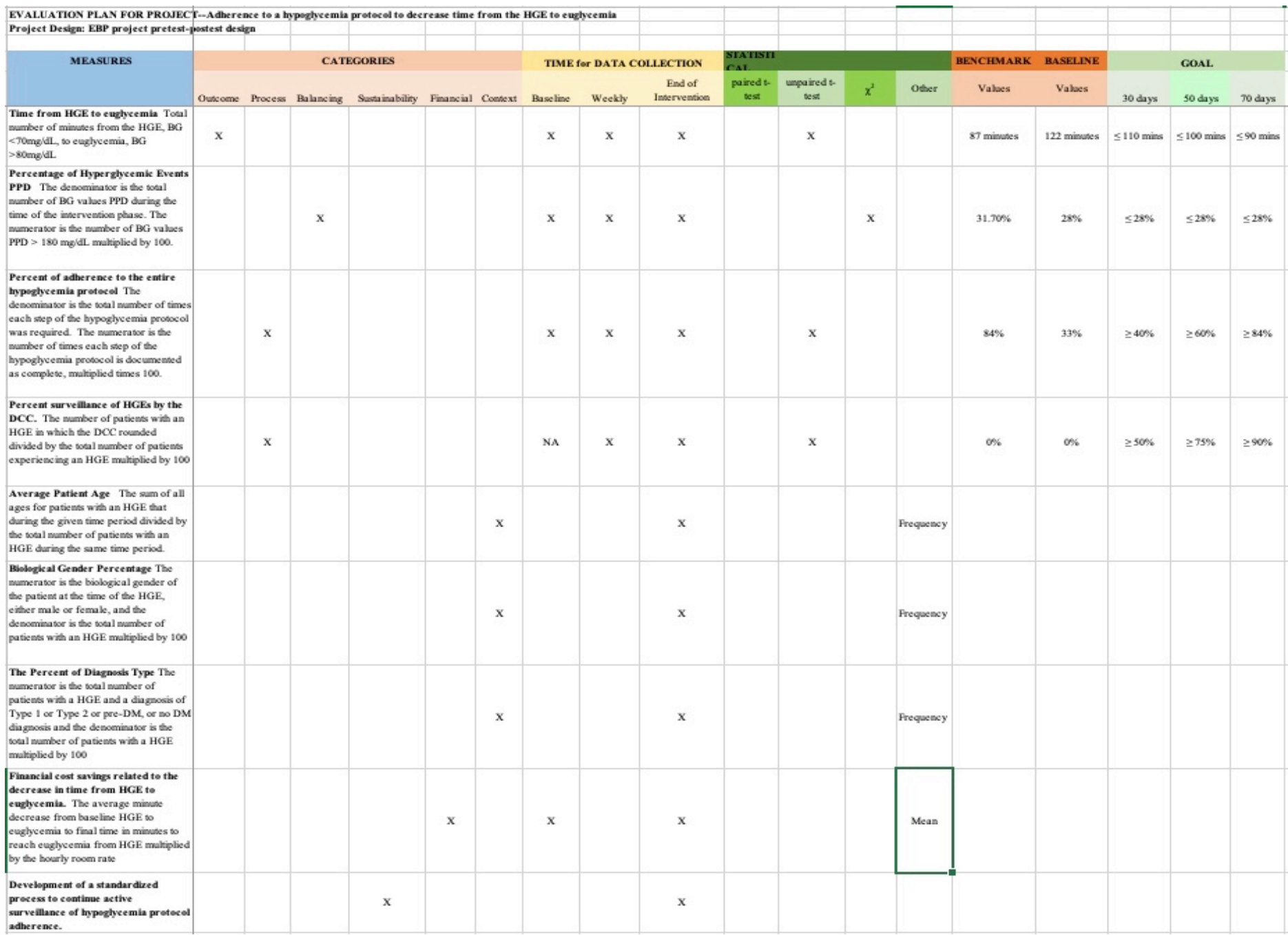




\section{Appendix H}

\section{Raw Data}

Descriptives

Included Variables:

Age, Gender, and Diagnosis

Sample Size (Complete Cases):

$\mathrm{N}=112$

Summary Statistics: Frequency Table for Nominal Variables

\begin{tabular}{|c|c|c|}
\hline Variable & $\mathrm{n}$ & \% \\
\hline \multicolumn{3}{|l|}{ Gender } \\
\hline Male & 55 & 49.107 \\
\hline Female & 57 & 50.893 \\
\hline Missing & 0 & 0.000 \\
\hline \multicolumn{3}{|l|}{ Diagnosis } \\
\hline None & 32 & 28.571 \\
\hline Type 2 & 70 & 62.500 \\
\hline Type 1 & 7 & 6.250 \\
\hline Pre & 3 & 2.679 \\
\hline Missing & 0 & 0.000 \\
\hline
\end{tabular}

Summary Statistics: Scale

\begin{tabular}{|c|c|c|c|c|c|c|c|c|}
\hline Variable & $\mathrm{M}$ & SD & $\mathrm{n}$ & $\mathrm{SE}_{\mathrm{M}}$ & Min & $\operatorname{Max}$ & Skewness & Kurtosis \\
\hline Age & 64.812 & 14.267 & 112 & 1.348 & 25.000 & 95.000 & -0.734 & 0.402 \\
\hline
\end{tabular}

Quantiles : 


\begin{tabular}{|l|l|l|}
\hline $20 \%$ & 55.000 \\
\hline $25 \%$ & 56.000 \\
\hline $30 \%$ & 56.900 \\
\hline $40 \%$ & 65.000 \\
\hline $50 \%$ & 68.000 \\
\hline $60 \%$ & 69.600 \\
\hline $70 \%$ & 72.000 \\
\hline $75 \%$ & 73.000 \\
\hline $80 \%$ & 78.000 \\
\hline $90 \%$ & 82.000 \\
\hline
\end{tabular}

\section{Descriptives}

Included Variables:

Age, Gender, and Diagnosis

Sample Size (Complete Cases):

$\mathrm{N}=236$

Summary Statistics: Frequency Table for Nominal Variables

\begin{tabular}{|c|c|c|}
\hline Variable & $\mathrm{n}$ & $\%$ \\
\hline \multicolumn{3}{|l|}{ Gender } \\
\hline Male & 150 & 63.559 \\
\hline Female & 86 & 36.441 \\
\hline Missing & 0 & 0.000 \\
\hline \multicolumn{3}{|l|}{ Diagnosis } \\
\hline None & 60 & 25.424 \\
\hline Type 2 & 136 & 57.627 \\
\hline Type 1 & 39 & 16.525 \\
\hline Pre & 1 & 0.424 \\
\hline Missing & 0 & 0.000 \\
\hline
\end{tabular}

Summary Statistics: Scale 


\begin{tabular}{|c|c|c|c|c|c|c|c|c|}
\hline Variable & M & SD & $\mathrm{n}$ & $\mathrm{SE}_{\mathrm{M}}$ & Min & $\operatorname{Max}$ & Skewness & Kurtosis \\
\hline Age & 64.441 & 16.067 & 236 & 1.046 & 24.000 & 104.000 & -0.368 & -0.271 \\
\hline
\end{tabular}

Quantiles:

\begin{tabular}{|l|l|l|}
\hline & Age \\
\hline $10 \%$ & 45.000 \\
\hline $20 \%$ & 49.000 \\
\hline $25 \%$ & 53.750 \\
\hline $30 \%$ & 57.000 \\
\hline $40 \%$ & 62.000 \\
\hline $50 \%$ & 67.000 \\
\hline $60 \%$ & 70.000 \\
\hline $70 \%$ & 73.000 \\
\hline $75 \%$ & 76.000 \\
\hline $80 \%$ & \\
\hline $90 \%$ & \\
\hline
\end{tabular}

\section{Independent t-Test for TTN by Group}

Included Variables:

TTN and Group

Sample Size (Complete Cases):

$\mathrm{N}=348$

Shapiro-Wilk Test:

Pre: $\mathrm{W}=0.643, \mathrm{p}=4.098 \mathrm{e}-15$

Post: $\mathrm{W}=0.433, \mathrm{p}=1.058 \mathrm{e}-26$

Overall: $\mathrm{W}=0.503, \mathrm{p}=4.558 \mathrm{e}-30$

Levene's Test:

$\mathrm{df}_{\mathrm{n}}=1, \mathrm{df}_{\mathrm{d}}=346, \mathrm{~F}=1.568, \mathrm{p}=0.21$

Results: 


\begin{tabular}{|c|c|c|c|c|c|c|}
\hline Variable & M & SD & M & SD & d \\
\hline TTN & 123.571 & 169.804 & 97.559 & 178.552 & 1.290 \\
\hline
\end{tabular}

Note. $\mathrm{n}=348, \mathrm{df}=346.000$.

Confidence Interval Based on $\alpha=0.05$ :

Lower Limit $=-13.661$, Mean Difference $=26.012$, Upper Limit $=65.685$

\section{Two-Tailed Mann Whitney U Test for TTN by Group}

Included Variables:

TTN and Group

Sample Size (Complete Cases):

$\mathrm{N}=348$

Results :

$\mathrm{U}=14463.000, \mathrm{z}=-1.422, \mathrm{p}=0.15$

Medians for TTN by Group

Pre $=49.500$ and Post $=44.500$

\section{Chi-square Test of Independence for Group and Total_Compliance}

Included Variables:

Total_Compliance and Group

Sample Size (Complete Cases):

$\mathrm{N}=348$

Frequency Table:

\begin{tabular}{|c|c|c|c|c|c|}
\hline & Total & & & & \\
\hline Group & Yes & No & $\chi^{2}$ & $d f$ & $\mathrm{p}$ \\
\hline Pre & $6[10.621]$ & $106[101.379]$ & 3.275 & 1 & 0.07 \\
\hline Post & $27[22.379]$ & $209[213.621]$ & & & \\
\hline
\end{tabular}

Note. Values formatted as Observed[Expected]

Chi-square Test of Independence Results:

$\chi^{2}=3.275, \mathrm{df}=1, \mathrm{p}=0.07$, Cramér's $\mathrm{V}=0.097$ 


\section{Paired t-Test for Pre and Post Test}

Included Variables:

Pre and Post

Sample Size (Complete Cases):

$\mathrm{N}=189$

Shapiro-Wilk Test:

$\mathrm{W}=0.940, \mathrm{p}=4.110 \mathrm{e}-07$

Levene's Test:

$d f_{n}=1, d f_{d}=376, F=58.140, p=2.015 e-13$

Results :

\begin{tabular}{|c|c|c|c|c|c|c|}
\hline \multicolumn{2}{|c|}{ Pre } & \multicolumn{2}{|c|}{ Post } & \multirow[b]{2}{*}{$t$} & \multirow[b]{2}{*}{$\mathrm{p}$} & \multirow[b]{2}{*}{$\mathrm{d}$} \\
\hline M & $\mathrm{SD}$ & M & $\mathrm{SD}$ & & & \\
\hline 68.836 & 18.152 & 93.704 & 8.058 & -18.483 & $3.776 e-44$ & 1.344 \\
\hline
\end{tabular}

Note. $\mathrm{n}=189, \mathrm{df}=188$

Confidence Interval Based on $\alpha=0.05$ :

Lower Limit $=-27.522$, Mean Difference $=-24.868$, Upper Limit $=-22.214$

\section{Two-Tailed Wilcoxon Signed Rank Test for Pre and Post}

Included Variables:

Pre and Post

Sample Size (Complete Cases):

$\mathrm{N}=189$

Results :

$\mathrm{V}=60.000, \mathrm{z}=-11.210, \mathrm{p}=3.641 \mathrm{e}-29$

Medians :

Pre $=70.000$ and Post $=100.000$ 